\title{
Amaryllidaceae S.S. E Alliaceae S.S. no Nordeste Brasileiro ${ }^{1}$
}

\author{
Anderson Alves-Araújo ${ }^{2}$, Julie Henriette Antoinette Dutilh ${ }^{3}$ \& Marccus Alves ${ }^{4}$
}

\begin{abstract}
RESUMo
(Amaryllidaceae s.s. e Alliaceae s.s. no Nordeste Brasileiro) O presente levantamento de Amaryllidaceae s.s. e Alliaceae s.s. no Nordeste do Brasil registrou 22 espécies. Amaryllidaceae está representada por 20 espécies e quatro gêneros: Griffinia (8 spp.), Habranthus (6), Hippeastrum (5) e Hymenocallis (1 spp.); e Alliaceae por duas espécies de Nothoscordum. São apresentadas chaves de identificação, descrições, ilustrações e dados sobre o habitat e distribuição geográfica das espécies no Nordeste.
\end{abstract}

Palavras-chave: monocotiledôneas, taxonomia, florística, Caatinga, Mata Atlântica.

\section{Abstract}

(Amaryllidaceae s.s. and Alliaceae s.s. in Notheastern Brazil) The present survey of the Brazil northeastern Amaryllidaceae s.s. and Alliaceae s.s. has recorded 22 species. Amaryllidaceae is represented by 20 species and four genera: Griffinia (8 spp.), Habranthus (6), Hippeastrum (5), and Hymenocallis (1); and Alliaceae by two Nothoscordum spp. Identification keys, descriptions and illustrations are provided, alongside with habitat and distribution data in the Northeastern Brazil.

Key words: monocots, taxonomy, floristics, plant survey, Caatinga, Atlantic Rain Forest.

\section{INTRODUÇÃO}

A proximidade filogenética entre Amaryllidaceae e Alliaceae já foi motivo de discussão. Traub (1963) posicionou Alliaceae como subfamília (Allioideae) de Amaryllidaceae, enquanto Cronquist (1981) reuniu ambas as famílias, juntamente com Alstroemeriaceae, Asparagaceae, Hiacynthaceae e Hypoxidaceae, dentre outras, no grande táxon Liliaceae s.l. Segundo APG II (2003), Amaryllidaceae s.s., juntamente com Alliaceae s.s. e Agapanthaceae, está subordinada à Alliaceae s.l.; mostrando que os três táxons são monofiléticos, e proximamente relacionados.

Alliaceae s.s. inclui entre 12 e 15 gêneros e cerca de 600 espécies, estando amplamente distribuída no globo. No neotrópico, a família está representada por três gêneros e aproximadamente 20 espécies (Meerow 2004), das quais apenas duas de Nothoscordum ocorrem no Nordeste brasileiro (Ravenna 1991, 2002). Amaryllidaceae s.s. é constituída por cerca de 60 gêneros e 850 espécies, possuindo ampla distribuição geográfica, com três centros de diversidade principais: América do Sul, sul da África e região do Mediterrâneo (Meerow 2004). No Brasil, ocorrem aproximadamente 15 gêneros e cerca de 150 espécies. Cerca de 30 foram inicialmente citadas para a Região Nordeste (Dutilh 2003), número reduzido para 19 táxons (Dutilh 2006) devido, principalmente, ao elevado número de sinônimos.

O presente trabalho visa caracterizar morfologicamente as espécies de Amaryllidaceae s.s. e Alliaceae s.s. nativas do Nordeste brasileiro, bem como fornecer dados sobre sua distribuição geográfica, ambientes de ocorrência e breves comentários fenológicos.

\section{Material e Métodos}

A Região Nordeste do Brasil ocupa uma área de cerca de $1.600 .000 \mathrm{~km}^{2}$, com clima quente, predominando o semi-árido, variando de tropical semi-úmido a úmido (IBGE 1977), e incluindo diversos tipos vegetacionais. Para melhor entendimento do complexo vegetacional, segue-se Coutinho (2006), onde as áreas visitadas

Artigo recebido em 02/2008. Aceito para publicação em 01/2009.

${ }^{1}$ Parte da dissertação do primeiro autor.

${ }^{2}$ Curso de Pós-Graduação em Biologia Vegetal - PPGBV, Departamento de Botânica, Universidade Federal de Pernambuco, 50670-901, Recife, PE, Brasil. agalves_araujo@hotmail.com

${ }^{3}$ Departamento de Botânica, Universidade Estadual de Campinas, Campinas, SP, Brasil.

${ }^{4}$ Departamento de Botânica, Universidade Federal de Pernambuco, 50670-901, Recife, PE, Brasil. 
distribuem-se pelos zonobiomas: Litobioma II, Psamobioma I e Zonobiomas I e II.

Foram realizadas coletas durante o período de outubro/2004 a junho/2006, ao longo de diferentes formações vegetacionais nos estados de Alagoas, Bahia, Ceará, Maranhão, Paraíba, Pernambuco, Piauí, Rio Grande do Norte e Sergipe. Os "vouchers" foram depositados no Herbário UFP e duplicatas doadas a herbários do Brasil e do exterior. Amostras coletadas em estádio vegetativo foram transportadas à casa de vegetação do Centro de Ciências Biológicas - CCB/UFPE e mantidas sob cultivo para acompanhamento do florescimento das mesmas.

Foram consultadas as coleções botânicas dos herbários ASE, BHCB, BOTU, CEPEC, EAC, HUEFS, IPA, JPB, K, MAC, MBM, NY, PEUFR, R, RB, SPF, TEPB, UEC, UFP, UPCB, US (siglas de acordo com Holmgren \& Holmgren (2006)), Herbário Sérgio Tavares (HST) e Herbário do Trópico Semi-Árido (TSAH). As identificações foram realizadas com auxílio de chaves de identificação e os dados ecológicos obtidos a partir das observações de campo e das etiquetas de herbário. Mapas de distribuição geográfica foram confeccionados a partir do georreferenciamento das áreas visitadas, dos dados de herbário e de referências bibliográficas.

A maioria das medidas foram obtidas a partir de exemplares frescos, a exceção de Griffinia espiritensis var. bahiana e Hymenocallis littoralis as quais foram obtidas a partir de espécimes sob condições de cultivo; e para Hippeastrum solandriflorum, as quais foram tomadas exclusivamente a partir de exsicatas, pois a espécie não foi encontrada no campo. O tamanho das flores refere-se ao somatório das medidas do comprimento do hipanto e da tépala de maior dimensão. As espécies não encontradas no campo e com baixa representatividade nas coleções consultadas estão apresentadas sob a forma de diagnoses e incluídas na chave de identificação a partir de informações complementadas com dados bibliográficos. A terminologia morfológica seguiu a proposta por Font Quer (1989), Harris \& Harris (1994), Meerow \& Snijman (1998) e Dutilh (2005).

\section{Resultados e Discussão}

Foram registradas, para o nordeste do Brasil, 20 espécies nativas pertencentes a quatro gêneros de Amaryllidaceae s.s., bem como duas espécies de Nothoscordum (Alliaceae s.s.). Optou-se por tratar as espécies Griffinia ilheusiana Ravenna como sinônimo de G. intermedia e G. mucurina e $G$. paubrasilica como sinônimos de $G$. espiritensis, seguindo o sugerido por Preuss \& Meerow (2001a). Griffinia aracensis Ravenna consta como táxon provavelmente ocorrente no leste da Bahia. Contudo, este dado resume-se à suposta distribuição da espécie a partir de dados bibliográficos (Preuss 1999). Tampouco "vouchers" disponíveis da referida espécie foram detectados nas coleções consultadas.

Adicionalmente, ainda dentre as espécies relacionadas por Dutilh (2006) estão Cearanthes fuscoviolacea Ravenna e Crinum americanum L., que não foram incluídos no presente trabalho devido à inacessibilidade ao material herborizado e não terem sido encontradas durante as expedições de campo. Ravenna (2000a) descreve Cearanthes fuscoviolacea como espécie próxima à Griffinia, tendo sido coletada no estado do Ceará, porém o material indicado pelo autor como depositado no RB, não foi localizado. Já Crinum americanum, embora referida como nativa do estado de São Paulo (Dutilh 2005), está incluída na listagem de plantas nordestinas devido à ampla distribuição do gênero na América do Sul. Porém, a própria autora ressalta a importância da realização de uma análise mais criteriosa.

As espécies estudadas ocorrem em áreas costeiras - Psamobioma I (Hymenocallis littoralis Salisb.); Mata Atlântica - Zonobioma I (Griffinia alba, G. espiritensis Ravenna var. bahiana, G. itambensis, G. intermedia e $G$. 
parviflora (muitas das espécies de G. subg. Griffinia são localmente conhecidas como Carícia), Hippeastrum puniceum; na Caatinga - Zonobioma II (Griffinia gardneriana, Habranthus bahiensis, $H$. datensis, $H$. aff. itaobinus, Hippeastrum glaucescens, $H$. reticulatum, $H$. solandriflorum, Nothoscordum bahiense e N. pernambucanum); e Cerrado - Piro-peinobioma II (Griffinia nocturna e Hippeastrum solandriflorum). Hippeastrum stylosum (cebola-brava, cebola-de-cobra) apresentou a maior abrangência de habitats relacionada ao gradiente de umidade, tendo sido coletada e registrada em todos os zonobiomas acima citados além dos Litobiomas II. As espécies de Habranthus foram encontradas em solos rasos de afloramentos rochosos - litobiomas II (H. itaobinus) e em solos profundos de caatinga de areia ou argilosos - zonobioma II (H. itaobinus, $H$. robustus, $H$. sylvaticus). Os representantes deste gênero são localmente conhecidos como lírios-de-chuva por florescerem após o início das chuvas nas áreas mais secas do nordeste.

\section{Chave de identificação das espécies de Alliaceae s.s. e Amaryllidaceae s.s. ocorrentes no Nordeste brasileiro}

1. Ovário súpero

Nothoscordum (Alliaceae)

2. Estilete ca. $3 \mathrm{~mm}$ compr., 1 óvulo/lóculo 22. N. bahiense

2'. Estilete 4-5 mm compr., 2 óvulos/lóculo 10. N. pernambucanum

1'. Ovário ínfero Amaryllidaceae

3. Inflorescência uniflora.

4. Brácteas da inflorescência livres, hipanto $>7 \mathrm{~cm}$ compr., estigma trilobado (Fig. 5c) 7. Hippeastrum solandriflorum

4'. Brácteas da inflorescência em parte fusionadas, hipanto $<30 \mathrm{~mm}$ compr., estigma trilobado a trífido (Fig. 41) Habranthus

5. Hipanto $\leq 5 \mathrm{~mm}$ compr., flores infundibuliformes a crateriformes.

6. Estames heterodínamos.

7. Folhas filiformes, paraperigônio setiforme, estigma trilobado 17. H. bahiensis

7'. Folhas lineares, paraperigônio fimbriado, estigma trífido ... 18. H. datensis 6'. Estames tridínamos.

8. Flores $<6 \mathrm{~cm}$ compr., ovário $<7 \mathrm{~mm}$ compr...... 19. H. aff. itaobinus

8'. Flores $>7 \mathrm{~cm}$ compr., ovário $>8 \mathrm{~mm}$ compr.

4. H. robustus

5'. Hipanto $>5 \mathrm{~mm}$ compr., flores crateriformes.

10. Hipanto até $1 \mathrm{~cm}$ compr., base das tépalas verde, tépalas alvas a róseas no ápice, tépala externa superior $<4 \times 1 \mathrm{~cm}$

3. H. itaobinus

10 '. Hipanto $>1 \mathrm{~cm}$ compr., base das tépalas verde a vinácea, tépalas róseas a alaranjadas com anel alvo na região mediana, tépala externa superior $>6 \times$ $1 \mathrm{~mm}$ 5. H. sylvaticus

3'. Inflorescência multiflora (raro biflora).

11'. Escapo cilíndrico, fistuloso

Hippeastrum

12. Paraperigônio ausente.

13. Hipanto $<3 \mathrm{~cm}$ compr., estigma capitado (Fig. $2 \mathrm{~g}$ ) .......21. H. reticulatum

13 '. Hipanto $>7 \mathrm{~cm}$ compr., estigma trilobado 7. H. solandriflorum

12'. Paraperigônio presente (Fig. 4h).

14. Paraperigônio denteado, ovário $>10 \mathrm{~mm}$ compr. 20. H. glaucescens 14'. Paraperigônio fimbriado, ovário $\leq 10 \mathrm{~mm}$ compr.

15. Estames tridínamos, anteras amarelas, anel alvo a creme na região mediana das tépalas 6. H. puniceum 
15'. Estames isodínamos, anteras creme com faixas vináceas, anel na região mediana das tépalas ausente

8. H. stylosum

11'. Escapo biconvexo, sólido ou sólido apenas na base.

16. Flores sésseis, actinomorfas, hipanto $>20 \mathrm{~cm}$ compr., corona estaminal presente, estames isodínamos 9. Hymenocallis littoralis

16 '. Flores subsésseis a pediceladas, zigomorfas, hipanto $\leq 5 \mathrm{~cm}$ compr., corona estaminal ausente, estames heterodínamos

Griffinia

17. Flores alvas, inflorescência 2-4-flora.

18. Flores pediceladas, hipanto $2-4 \mathrm{~mm}$ compr.

2. G. gardneriana

18'. Flores subsésseis, hipanto 10-50 mm compr.

16. G. nocturna

17'. Flores lilás (raro alvas), inflorescência 4-17-flora.

19. Folha ca. $40 \mathrm{~cm}$ compr., escapo 35-38 cm compr., inflorescência 16 - 17-flora, flores alvas 11. G. alba

19'. Folha $\leq 35$ cm compr., escapo < 35 cm compr., inflorescência até 15-flora, flores lilás.

20. Folhas ovadas a ovado-elípticas, escapos $\geq 20 \mathrm{~cm}$ compr.

21. Pseudopecíolo e escapo avermelhados na base, folhas ovadas, escapo $<30 \mathrm{~cm}$ compr., inflorescência 10-15-flora 15. G. parviflora

21'. Pseudopecíolo e escapos esverdeados, folhas ovado-elípticas, escapo $30 \mathrm{~cm}$ compr., inflorescência 6-10-flora 14. G. intermedia

20'. Folhas sagitadas, lanceoladas ou elíptico-lanceoladas, escapos $<20 \mathrm{~cm}$ compr.

22. Folhas longo-pseudopecioladas (ca. $35 \mathrm{~cm}$ compr.), folhas sagitadas..... 12. G. arifolia

22'. Folhas curto-pseudopecioladas ( $<20 \mathrm{~cm}$ compr.), folhas lanceoladas ou elíptico-lanceoladas.

23. Hipanto 2-3 mm compr., tépalas lilás com raio longitudinal alvo, inflorescência 4-7-flora 1. G. espiritensis var. bahiana 23'. Hipanto 1,5 mm compr., tépalas lilás com base alva, inflorescência 7-11-flora 13. G. itambensis

\section{Griffinia Ker Gawl.}

Folhas perenes ou anuais, sésseis ou pseudopecioladas. Escapo biconvexo, geralmente sólido; brácteas da inflorescência2, livres a parcialmente fusionadas em um dos lados. Inflorescência multiflora. Flores pediceladas, não-odoríferas e antese diurna (subg. Griffinia) ou odoríferas e antese noturna (subg. Hyline), zigomorfas, tépala inferior interna declinada. Estames-5(6), declinadoascendentes. Ovário ínfero; estigma capitado.

1. Griffinia espiritensis var. bahiana Preuss \& Meerow, Herbertia 56: 123. 2001.

Figs. 1a, 2a-c, 3a

Bulbo oblato; colo 1-1,2 mm compr., nãodecurrente. Folhas $(14,7-) 16,5(-19) \times(2,4-)$
3,2(-4) cm, perenes, dísticas, eretas, pseudopecíolo (5-10 cm compr.) canaliculado, elíptico-lanceoladas, nervura central proeminente na face abaxial, face adaxial verde-brilhante, face abaxial verde-hialina, ápice agudo, margens inteiras, onduladas. Inflorescência 4-7-flora, umbeliforme; escapo 10,5-12 cm compr., sólido, verde-claro, verde-hialino na base; brácteas 1,1-2 mm compr., espatáceas, em parte fusionadas em um dos lados, hialinas. Flores declinadas, infundibuliformes, inodoras, hipanto $2-3 \mathrm{~mm}$ compr., pedicelo 6-15 mm compr.; tépalas-6, lilás com raio longitudinal alvo e base alva, reflexas, 5 tépalas $22-25 \times 4-5 \mathrm{~mm}$, declinadaascendentes, 1 tépala interna inferior 22-25 $\times$ ca. $2 \mathrm{~mm}$, declinada; estames-5, declinado- 

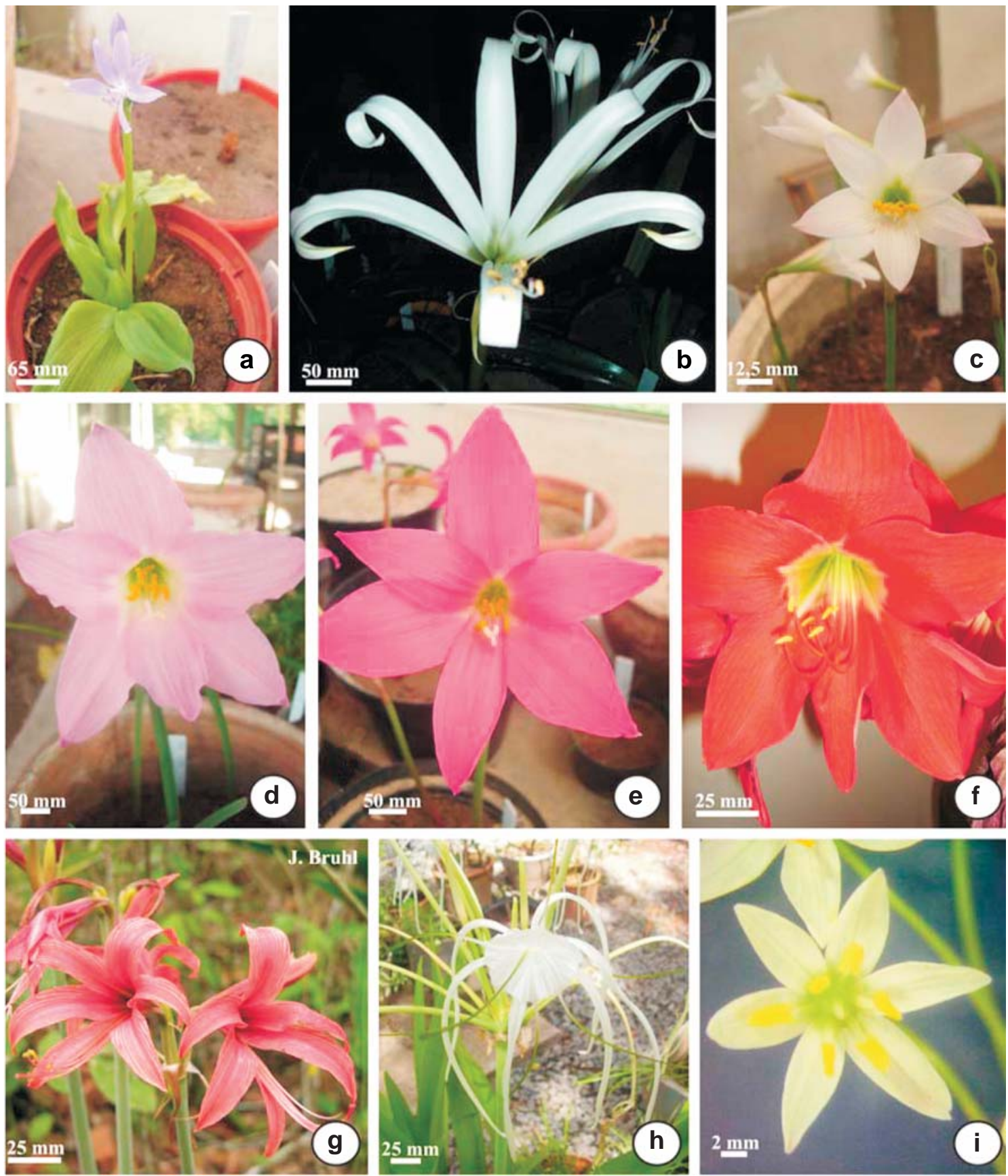

Figura 1 - a. Griffinia espiritensis Rav. var. bahiana Preuss \& Meerow (Alves-Araújo 37); b. Griffinia gardneriana (Herb.) Rav. (Alves-Araújo 33); c. Habranthus itaobinus Rav. (Alves-Araújo 36); d. Habranthus robustus Herb. ex Sweet. (Alves-Araújo 43); e. Habranthus sylvaticus Herb. (Alves-Araújo 30); f. Hippeastrum puniceum (Lam.) Kuntze. (Alves-Araújo 40); g. Hippeastrum stylosum Herb. (Alves-Araújo 21); h. Hymenocallis littoralis Salisb. (Alves-Araújo 54); i. Nothoscordum pernambucanum Rav. (Alves-Araújo 76).

Figure 1 - a. Griffinia espiritensis Rav. var. bahiana Preuss \& Meerow (Alves-Araújo 37); b. Griffinia gardneriana (Herb.) Rav. (Alves-Araújo 33); c. Habranthus itaobinus Rav. (Alves-Araújo 36); d. Habranthus robustus Herb. ex Sweet. (AlvesAraújo 43); e. Habranthus sylvaticus Herb. (Alves-Araújo 30); f. Hippeastrum puniceum (Lam.) Kuntze. (Alves-Araújo 40); g. Hippeastrum stylosum Herb. (Alves-Araújo 21); h. Hymenocallis littoralis Salisb. (Alves-Araújo 54); i. Nothoscordum pernambucanum Rav. (Alves-Araújo 76). 
ascendentes, heterodínamos, 2 estames 14-15 mm, 3 estames 9-10 mm compr., dialistêmones, filetes lilás, bases alvas; anteras lilás, pólen alvo; ovário 4-5 mm compr., verde, óvulos-2 por lóculo; estilete 19-25 mm compr., lilás, base alva, estigma alvo. Frutos globosos, verdes.

Semente-1 por fruto, globosa, verde.

Material examinado selecionado: BRASIL. BAHIA: Colônia da Bahia, 23.II.1990, fl., J. Dutilh s.n. (UEC 23097); Mucuri, 20.V.1980, fl., L. Mattos Silva \& T. Santos s.n. (CEPEC 768); Una, 14.IX.1993, fl., A. Amorim et al. 1350 (CEPEC); PERNAMBUCO: Recife, Casa de Vegetação/CCB/UFPE - origem Cabo de Santo Agostinho, em cultivo, 31.XII.2005, fl., A. Alves-Araújo et al.37(UFP); SERGIPE: Nossa Senhora da Glória, 13.V.1982, fl., G. Viana 461 (ASE, IPA).

Griffinia espiritensis var. bahiana distribui-se nos estados do Espírito Santo e da Bahia (Preuss 1999; Preuss \& Meerow 2001a), sendo este o primeiro registro para Sergipe e Pernambuco. Os espécimes estudados do estado de Pernambuco são provenientes da Reserva Ecológica de Gurjaú, fragmento de MataAtlântica e foram mantidos em cultivo sob condições não controladas. Apresenta uma elevada produção de bulbilhos e florescimento ao longo de todo o ano, flores inodoras, antese diurna e botões em diferentes estádios de desenvolvimento simultaneamente. Distingue-se de G. alba, também posicionada no subg. Griffinia, pelo menor porte e pelas flores lilás, e de $G$. gardneriana, pertencente ao subg. Hyline, pela antese diurna e coloração das flores. Segundo Preuss \& Meerow (2001a), G. colatinensis Ravenna, $G$. mucurina Ravenna e $G$. paubrasilica Ker Gawler, cujo material foi consultado, tratam-se de possíveis variedades de G. espiritensis; dada à sobreposição dos caracteres analisados, optou-se por considerá-las como tal. Griffinia espiritensis var. bahiana distingue-se da variedades típica e da var. ituberae Preuss \& Meerow por apresentar menores dimensões e não possuir máculas alvas nas folhas.

2. Griffinia gardneriana (Herb.) Ravenna, Pl. Life 25: 62-63. 1969. Figs. 1b, 2d-g, 3a

Bulbo obovado a oblato; colo 4-9 cm compr. Folhas $(22-) 25,1(-28) \times(2,6-) 3,9$
$(-4,6) \mathrm{cm}$, decíduas, dísticas, levemente eretas a prostradas, sésseis, oblanceoladas, às vezes falcadas, nervura central pouco evidente, verde-escura a verde-clara em ambas as faces, levemente maculadas ou não na face adaxial, ápice agudo, margens inteiras, retas a levemente revolutas. Inflorescência 2-4flora, umbeliforme; escapo 10,2-25 cm compr., em parte sólido, fistuloso nos $2 / 3$ superiores, verde-claro a rosado, arestas verde-claras a vináceas; brácteas 5,5-8,5 cm compr., espatáceas, livres, verdes, alvo-amareladas ou róseas. Flores ascendentes, infundibuliformes, odoríferas, hipanto 2-4 mm compr., pedicelo 1,3-5,8 cm compr.; tépalas-6, alvas, bases verdes, presença ou não de uma faixa ao longo da nervura mediana na face abaxial das tépalas verde-clara a vinácea, fortemente reflexas, 5 tépalas $12,8-18,5 \times 1-2 \mathrm{~cm}$, declinada-ascendentes, 1 tépala interna inferior 12,4-17,5 cm ×8-20 mm, declinada, levemente canaliculada; estames-6, eretos, heterodínamos, 2 estames $10-13 \mathrm{~cm}, 1$ estame 10,4-13,5 cm, 1 estame 11,5-14 cm e 2 estames $11,7-15 \mathrm{~cm}$ compr., corona estaminal ausente, filetes concrescidos na base, alvos, anteras translúcidas a amarelo-claras, pólen amareloclaro; ovário 1,2-2 cm compr., verde, 20 óvulos por lóculo, estilete 13-17 cm compr., podendo formar um ângulo de $90^{\circ}$ no ápice; estigma alvo a roxo. Frutos globosos, 3-sulcados, verdes. Sementes globosas, verdes.

Material examinado selecionado: BRASIL. BAHIA: Itaju do Colônia, 23.X.1969, fl., T. Santos 415 (IPA); Santa Cruz das Vitórias, 19.XI.1973, fl., G. Barroso s.n. (RB 185203); MARANHÃO: Tuntum, 19.X.1976, fl., D. Andrade-Lima 13487 (PEUFR); PERNAMBUCO: Buíque, Parque Nacional do Catimbau, 30.VII.2005, fl., A. Alves-Araújo et al. 33 (IPA, UFP); Ouricuri, 28.II.1984, fl., G. Costa-Lima 3 (IPA); Petrolândia, 15.V.2004, fl., A. Silva 530 (PEUFR); PIAUÍ: Pedro II, 21.I.2005, fl., G. Sousa et al. 516 (TEPB); RIO GRANDE DO NORTE: Riacho Seco, 27.I.1961, fl., A. Castellanos 23039 (R).

Griffinia gardneriana ocorre na Bahia, Ceará, Maranhão, Pernambuco, Piauí e Rio Grande do Norte. É uma espécie típica de caatinga de areia (Zonobioma II), ocorrendo 


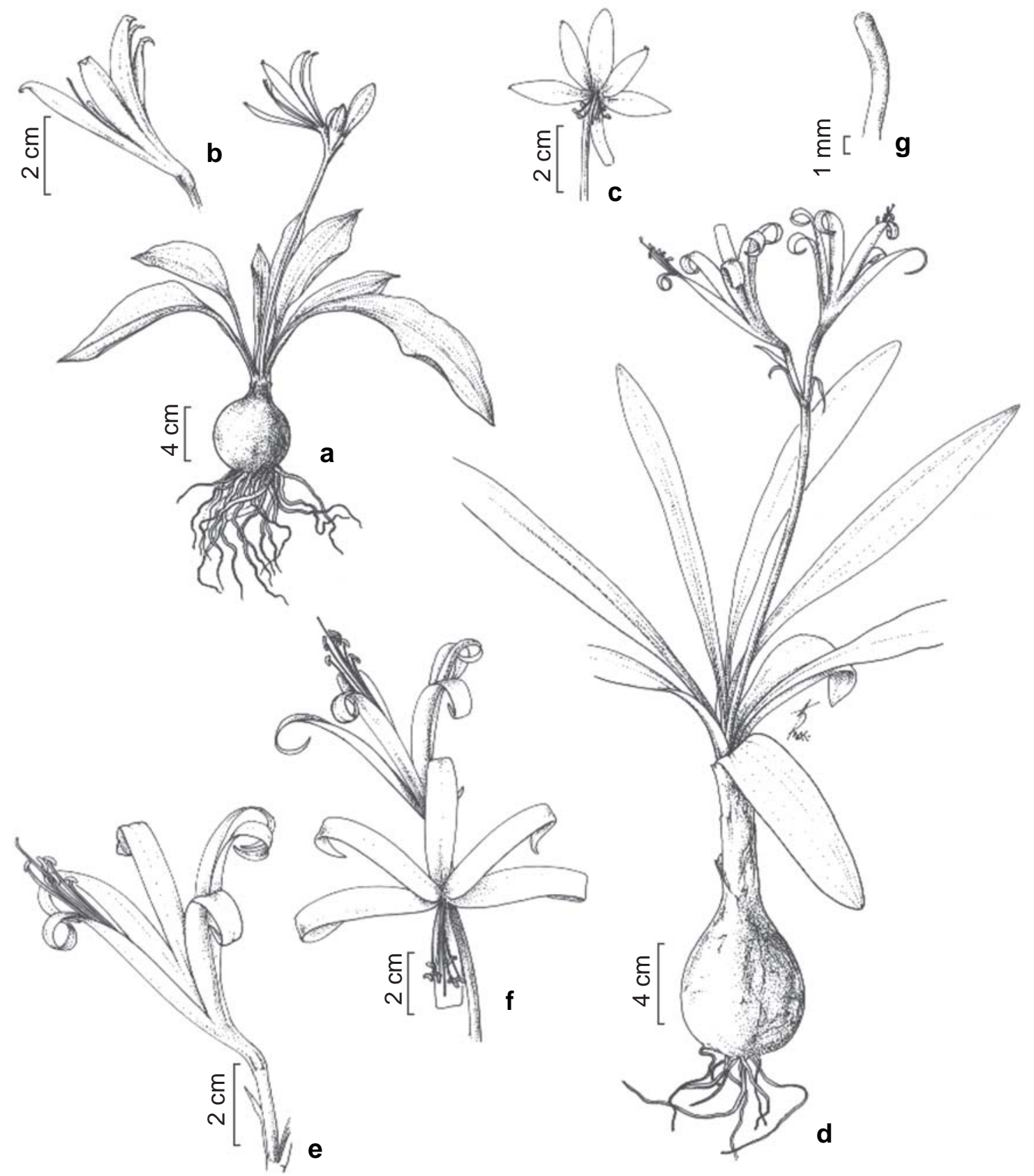

Figura 2 - Griffinia - a-c. G. espiritensis Rav. var. bahiana Preuss \& Meerow (Alves-Araújo 37) - a. hábito; b. flor em vista lateral; c. detalhe da flor em vista frontal. d-g. G. gardneriana (Herb.) Rav. (Alves-Araújo 33) - d. hábito; e. flor em vista lateral; f. flor em vista frontal; g. estigma capitado.

Figure 2 - Griffinia - a-c. G. espiritensis Rav. var. bahiana Preuss \& Meerow (Alves-Araújo 37) - a. habit; b. flower, lateral view; c. flower, frontal view. d-g. G. gardneriana (Herb.) Rav. (Alves-Araújo 33) - d. habit; e. flower, lateral view; f. flower, frontal view; g. capitate stigma. 
em áreas abertas, ou ainda, sob arbustos e em solos bem drenados. No Parque Nacional do Catimbau, a espécie possui uma densa população, o que pode ser melhor observado na estação chuvosa, uma vez que as folhas são decíduas no período seco. Em cultivo, a produção de bulbilhos laterais foi observada apenas sob condição de injúria do bulbo-mãe. Na natureza, floresce entre dezembro a março, porém obteve-se a floração dos indivíduos após tratamento de estresse hídrico durante aproximadamente quatro meses. Possui flores odoríferas, com antese noturna quase concomitante na mesma inflorescência e duração de uma noite. Griffinia gardneriana e G. nocturna são as únicas espécies do subg. Hyline (Preuss 1999), diferindo entre si principalmente pelo comprimento do hipanto que, em G. nocturna, mede $1-5 \mathrm{~cm}$.

\section{Habranthus Herb.}

Folhas perenes ou anuais, sésseis. Escapo cilíndrico, fistuloso; brácteas da inflorescência-2, parcialmente fusionadas, livres no ápice. Inflorescência uniflora. Flores pediceladas, não odoríferas e antese diurna, levemente zigomorfas. Estames-6, declinado-ascendentes. Ovário ínfero; estigma trilobado a trífido.

3. Habranthus itaobinus Ravenna, Onira Bot. Leafl., 3(16): 56. $1999 . \quad$ Figs. 1c, 3b, 4a-e

Bulbo obovado a ovado; colo $1-4,3 \mathrm{~cm}$ compr. Folhas $(16,5-) 30,8(41,5) \mathrm{cm} \times(3-)$ 4,5(-5) $\mathrm{mm}$, decíduas, dísticas, eretas, ensiformes, levemente canaliculadas, nervura central não conspícua, verde-brilhante em ambas as faces, ápice agudo, margens inteiras, retas. Escapo 11,5-26,3 cm compr., verdeclaro, base rósea; brácteas 17-28 mm compr., espatáceas, hialinas a alvo-esverdeadas. Flor declinada, crateriforme, hipanto 7-10 mm compr., paraperigônio formado por calosidades, pedicelo 2,7-5,5 cm compr.; tépalas-6, alvas a róseas no ápice, bases verdes, tépala externa superior 27-32 ×9-10 mm, tépalas externas laterais 27-32 ×7-8 mm, tépala interna inferior
26-30 $\times 6-8 \mathrm{~mm}$, tépalas internas laterais 27 $32 \times 7-8 \mathrm{~mm}$, levemente reflexas; estames tridínamos, 3 estames $15-20 \mathrm{~mm}$ e 3 estames 14-17 mm compr., dialistêmones, alvos a róseos, com base verdes, anteras amarelas, pólen amarelo-intenso; ovário 4-6 mm compr., verde, 22-24 óvulos por lóculo, estilete 2,1$2,5 \mathrm{~cm}$ compr., alvo, base verde; estigma trífido, alvo. Frutos depresso-globosos, verdes, 3sulcados. Sementes aladas, arredondadas a deltóides, marrons a enegrecidas.

Material examinado selecionado: BRASIL. BAHIA: Água Quente, 29.XI.1988, fl., R. Harley et al. 26699 (CEPEC); Feira de Santana, 19.XI.2005, fl., A. AlvesAraújo et al. 45 (UFP); Maracás, 12.X.1983, fl. e fr., A. Carvalho et al. s.n. (CEPEC 1960); CEARÁ: Quixadá, 18.I.2000, fl., L. Lima-Verde \& R. Oliveira 135 (EAC); PERNAMBUCO: Bezerros, 31.VII.2005, fl., A. Alves-Araújo et al. 36 (MBM, R, RB, UFP); Brejo da Madre de Deus, 15.VI.1973, fl., AndradeLima 7379 (IPA); Garanhuns, 1986, fl., R. Bedi 314 (IPA); Vertentes, 18.III.2006, fl., A. Alves-Araújo et al. 69 (UFP); Taquaritinga do Norte, 18.III.2006, fl., A. Alves-Araújo et al. 70 (UFP); SERGIPE: Gararu, 31.I.1983, fl., E. Gomes 154 (ASE).

Habranthus itaobinus distribui-se amplamente pela região Nordeste, ocorrendo também nas Regiões Centro-Oeste e Sudeste (Oliveira 2006). Foi coletada em áreas abertas, desde solos argilosos profundos a ilhas de solos rasos em "inselbergs". Na natureza, a floração ocorre entre novembro e março, porém foi induzida após quatro meses de estresse hídrico. É caracterizada pelo menor porte dentre os táxons do presente trabalho, além de flores alvas a levemente róseas com base verde. Pode ser diferenciada de $H$. sylvaticus através do comprimento das folhas e do hipanto e de $H$. robustus pelo comprimento e largura das folhas.

4. Habranthus robustus Herb. ex Sweet, Brit. Fl. Gard. 2(1):14. 1831. Figs. 1d, 3b, 4f-g Bulbo obovado a ovado; colo 3,5-5 cm compr. Folhas $(35,8-) 42,5(-48,7) \mathrm{cm}^{\prime}(9-)$ 11(-13) $\mathrm{mm}$, decíduas, dísticas, eretas, ensiformes, canaliculadas, nervura central não conspícua, verde-escuras em ambas as faces, ápice acuminado, margens inteiras, retas, revolutas ou não. Escapo 20-26 cm compr., verde; 

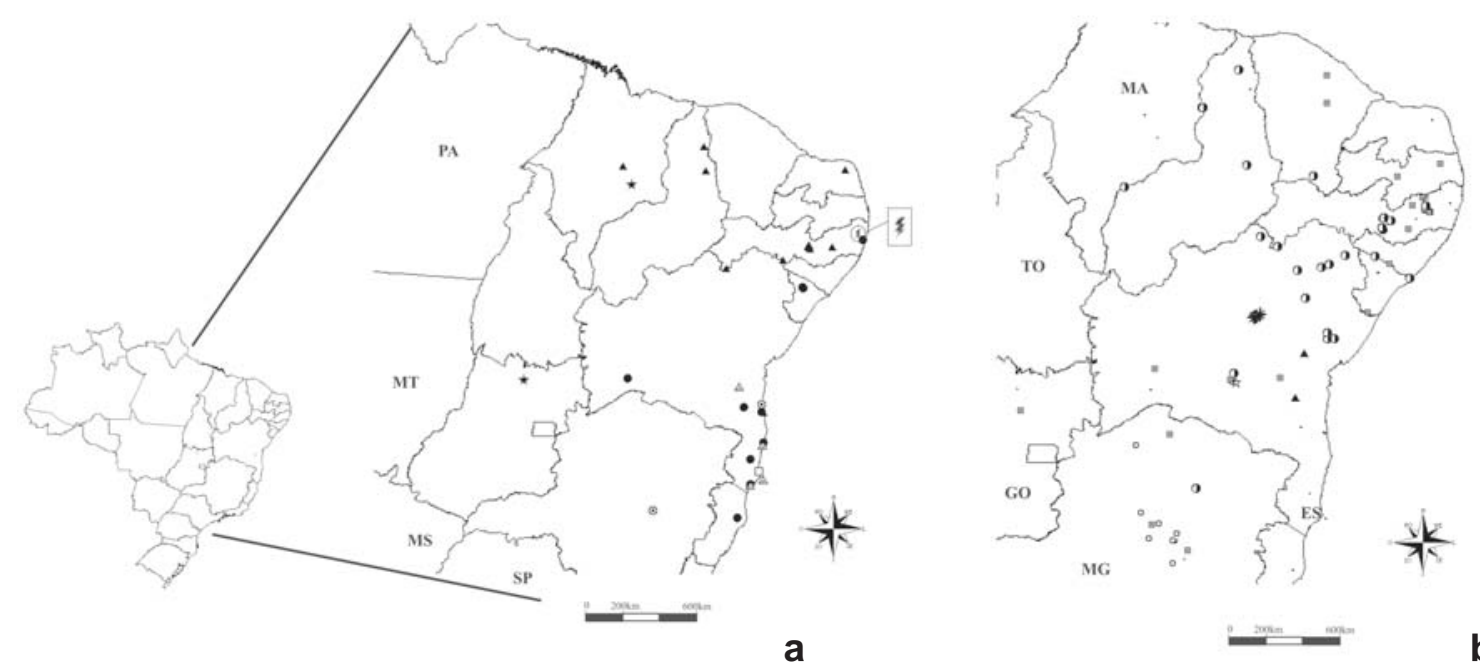

Figura 3 - Mapas de distribuição das espécies de Amaryllidaceae s.s. nordestinas. a. Griffinia Ker Gawler: • G. espiritensis Rav. var. bahiana Preuss \& Meerow; $\Delta$ G. gardneriana (Herb.) Rav.; $\bigcirc$ G. itambensis Rav.; ^ G. nocturna Rav.; $\triangle$ G. parviflora Ker Gawl.; G. alba Preuss \& Meerow; $\square$ G. arifolia Rav. b. Habranthus Herb.: * H. bahiensis Rav.; $\bigcirc$ H. datensis Rav.; $\square$ H. itaobinus Rav.; $\boldsymbol{\Delta}$ H. robustus Herb. ex Sweet.; O H. sylvaticus Herb.; is H. aff. itaobinus Rav.

Figure 3 - Distribution of Amaryllidaceae s.s. species from northeastern, Brasil. a. Griffinia Ker Gawler: $\bullet$ G. espiritensis Rav. var. bahiana Preuss \& Meerow; $\boldsymbol{\Delta}$ G. gardneriana (Herb.) Rav.; ○ G. itambensis Rav.; ^ G. nocturna Rav.; $\Delta$ G. parviflora Ker Gawl.; G. alba Preuss \& Meerow; $\square$ G. arifolia Rav. b. Habranthus Herb.: * H. bahiensis Rav.; $\bigcirc$ H. datensis Rav.; $\square$ H. itaobinus Rav.; $\boldsymbol{\Delta}$. robustus Herb. ex Sweet.; 1 . sylvaticus Herb.; is H. aff. itaobinus Rav.

brácteas 4-5 cm compr., espatáceas, verdeclaras. Flor declinada, infundibuliforme, hipanto 1-2 mm compr., paraperigônio ausente, pedicelo 6,8-7 cm compr.; tépalas-6, levemente reflexas, róseas a alvo-róseas, faixa alva na região mediana das tépalas com área variável, com base verde-clara, tépala externa superior $7-7,3^{\prime} 2,5-2,6 \mathrm{~cm}$, tépalas externas laterais $6,7-7,3^{\prime} 1,9-2 \mathrm{~cm}$, tépala interna inferior 7$7,1^{\prime} 1,5-1,7 \mathrm{~cm}$, tépalas internas laterais $6,5-$ 6,8 '1,9-2 cm; estames tridínamos, 3 estames 2-2,5 cm e 3 estames 2,9-3,5 cm compr., dialistêmones, filetes alvos, bases verdes, anteras amarelas, pólen amarelo-intenso; ovário 0,9-1 cm compr., verde-claro, 20-24 óvulos por lóculo, estilete 5,5-5,6 cm compr., alvo, base verde; estigma trífido, alvo. Frutos depresso-globosos, verdes, 3-sulcados. Sementes aladas, arredondadas a deltóides, marrons a enegrecidas.

Material examinado selecionado: BRASIL. BAHIA: Itatim, 28.IX.1996, fl. e fr., F. França 1839 (HUEFS); Morro do Chapéu, 11.XI.1998, fl., D. Carneiro et al. 49 (HUEFS); Rio de Contas, 28.X.1988, fl., R. Harley et al. 2712 (CEPEC); Material sem procedência, Casa de Vegetação/CCB/UFPE - origem imprecisa, 12.XII.2005, fl., A. Alves-Araújo et al. 43 (UFP).

Habranthus robustus está restrito ao estado da Bahia, ocorrendo em áreas abertas ou ainda sob arbustos, em solos bem drenados. Os espécimens analisados foram mantidos em casa de vegetação do Centro de Ciências Biológicas/ UFPE, com florescimento observado entre dezembro e janeiro, em condições de cultivo e não submetido a estresse hídrico. Caracterizase por possuir as flores róseas a alvo-róseas, o hipanto curto e a base das folhas e dos escapos verdes. Estas características são de fácil distinção quando comparadas às de $H$. sylvaticus, que possui hipanto longo, e $H$. itaobinus, pelo comprimento, largura e coloração das folhas, assim como pelas menores dimensões das flores.

5.Habranthus sylvaticus Herb., Amaryllidaceae: 166. 1837.

Figs. 1e, 3b, 4h-1

Bulbo obovado a ovado; colo $2-5 \mathrm{~cm}$ compr. Folhas $(33,6-) 42,6(-53,5) \mathrm{cm} \times(7-)$ 9(-11) mm, decíduas, dísticas, eretas, ensiformes, 
canaliculadas, nervura central não conspícua, verde-escuras em ambas as faces, base vinácea, ápice acuminado, margens inteiras, retas. Escapo 15-42,5 cm compr., verde-escuro, base verde a vinácea; brácteas 1,8-2,9 cm compr., espatáceas, hialinas, verdes a róseo-esverdeadas. Flor declinada, crateriforme, hipanto 1,3-2,5 cm compr., paraperigônio formado por apêndices recurvados, pedicelo $3,5-8 \mathrm{~cm}$ compr.; tépalas6 , leve a fortemente reflexas, róseas, rosa-intenso a alaranjadas, anel alvo na região mediana das tépalas, bases verdes a vináceas, tépala externa superior 6,3-7,2 $\times 1,5-2,2 \mathrm{~cm}$, tépalas externas laterais 5,5-7×1,5-2,2 cm, tépala interna inferior $5,5-6,5 \times 1,2-1,5 \mathrm{~cm}$, tépalas internas laterais 5,3-6,1 × 1,2-1,5 cm; estames tridínamos, 3 estames $1-2 \mathrm{~cm}$ e 3 estames $2-3,8 \mathrm{~cm}$ compr., dialistêmones, filetes alvos a róseos, bases alvas, anteras amarelas, pólen amarelo-intenso; ovário 4-6 mm compr., ínfero, verde a vináceo, 22-24 óvulos por lóculo; estilete 4,8-5,9 cm compr., alvo a róseo, base verde, estigma trífido, alvo. Frutos depresso-globosos, verdes, 3-sulcados. Sementes aladas, arredondadas a deltóides, marrons a enegrecidas.

Material examinado selecionado: BRASIL. ALAGOAS: Pão de Açúcar, 5.V.2002, fl., R. LyraLemos et al. 6702 (MAC); BAHIA: Andorinhas, 12.II.2006, fl., F. França et al. 5498 (HUEFS); Canudos, 29.X.2001, fl., L. Queiroz et al. 7046(HUEFS, PEUFR); Feira de Santana, fl., A. Alves-Araújo et al. 44 (UFP); Morro do Chapéu, 14.XI.2002, fl., M. Junqueira et al. 143 (HUEFS); Paulo Afonso, 30.XI.2005, fl., F. França et al. 5293 (HUEFS); CEARÁ: s.l., s.d., fl., F. Alemão \& M. Cisneiros 1529 (R); PERNAMBUCO: Buíque, Parque Nacional do Catimbau, 30.VII.2005, fl., A. Alves-Araújo et al. 30 (UFP, R, RB); 12.III.2006, fl.,A. Alves-Araújo et al. 68 (RB, UFP); Petrolina, 28.XII.1982, fl., G Foetius 3276 (IPA); PIAUÍ: Piracuruca, Parque Nacional de Sete Cidades, 30.I.1981, fl., R. Lyra 210 (MAC); Ribeiro Gonçalves, Estação Ecológica de Uruçuí, 15.X.1980, fl. e fr., A. Fernandes \& A. Castro s.n. (EAC 9371).

Habranthus sylvaticus é amplamente distribuído pelo nordeste, ocorrendo em áreas abertas e em solos bem drenados. No PARNA do Catimbau, observou-se uma grande variação da morfologia floral entre as populações acompanhadas, onde foram encontradas flores e folhas com diferentes padrões de coloração. A produção de bulbilhos laterais é rara, tanto em condições naturais quanto em cultivo. $\mathrm{Na}$ natureza, a floração foi observada entre dezembro e março e, em cultivo, após estresse hídrico de aproximadamente quatro meses. Pode ser distinta de $H$. robustus através do comprimento do hipanto, que alcança até $2,5 \mathrm{~cm}$, e do ovário (4-6 mm compr.). A presença de flores róseas a alaranjadas com anel alvo central e maior comprimento do estilete são importantes para a delimitação do táxon em relação à $H$. itaobinus.

\section{Hippeastrum Herb.}

Folhas geralmente anuais, sésseis. Escapo cilíndrico, geralmente fistuloso; brácteas da inflorescência-2, livres. Inflorescência multiflora (raro uniflora). Flores sésseis a pediceladas, não-odoríferas, antese geralmente diurna, zigomorfas. Estames-6, declinado-ascendentes a eretos. Ovário ínfero; estigma trilobado a capitado.

6. Hippeastrum puniceum (Lam.) Kuntze, Rev. Gen. Pl. 2:703. 1891. Figs. 1f, 5a-c, 6a

Bulbo ovado a orbicular; colo 3,2-5,5 cm compr. Folhas $(50,2-) 57(-65,8) \times(3-) 3,25$ $(-3,6) \mathrm{cm}$, decíduas, dísticas, eretas, sésseis, ensiformes a falcadas, nervura central não conspícua, verde-claras em ambas as faces, ápice agudo, margens inteiras, retas. Inflorescência 2-4-flora, umbeliforme; escapo 31-40 cm compr., fistuloso, verde; brácteas 6-7,1 cm compr., espatáceas, verdes a róseo-esverdeadas. Flores declinadas, infundibuliformes, hipanto 3-4 cm compr., paraperigônio fimbriado, pedicelo $4-4,8 \mathrm{~cm}$ compr.; tépalas-6, conjunto da tépala externa com as laterais internas (tépalas superiores) fortemente reflexo, alaranjadas a vermelhas, com base verde a vermelha, anel alvo a creme na região mediana das tépalas, tépala externa superior 6,8-7 × 3-3,2 cm, tépalas externas laterais $6,6-6,8 \times 2,6-2,8 \mathrm{~cm}$, tépala interna inferior $6-6,1 \times 2-2,2 \mathrm{~cm}$, tépalas internas laterais 6-6,1 $\times 2,4-2,7 \mathrm{~cm}$; estames tridínamos, 3 de 6,8-7 cm e 3 de 6-6,2 cm compr., 

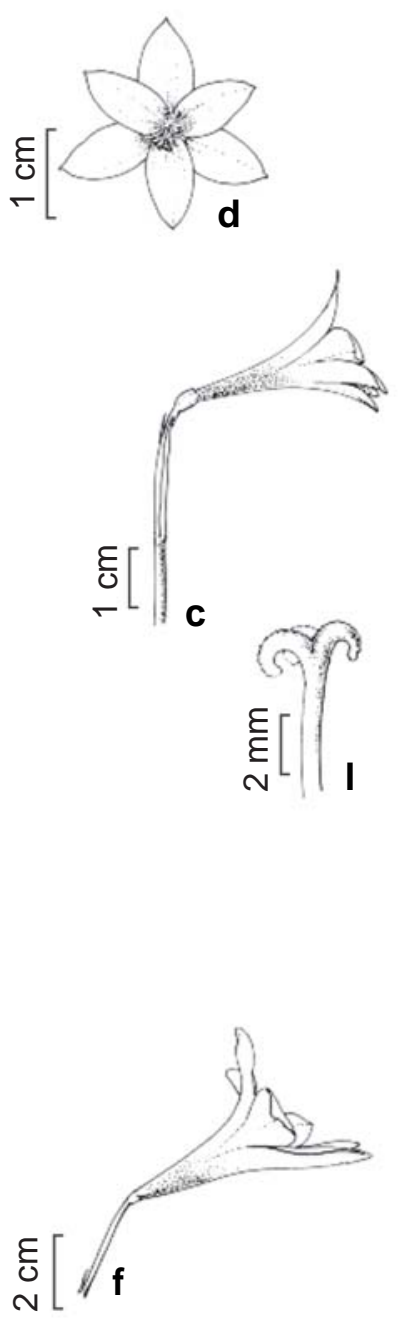
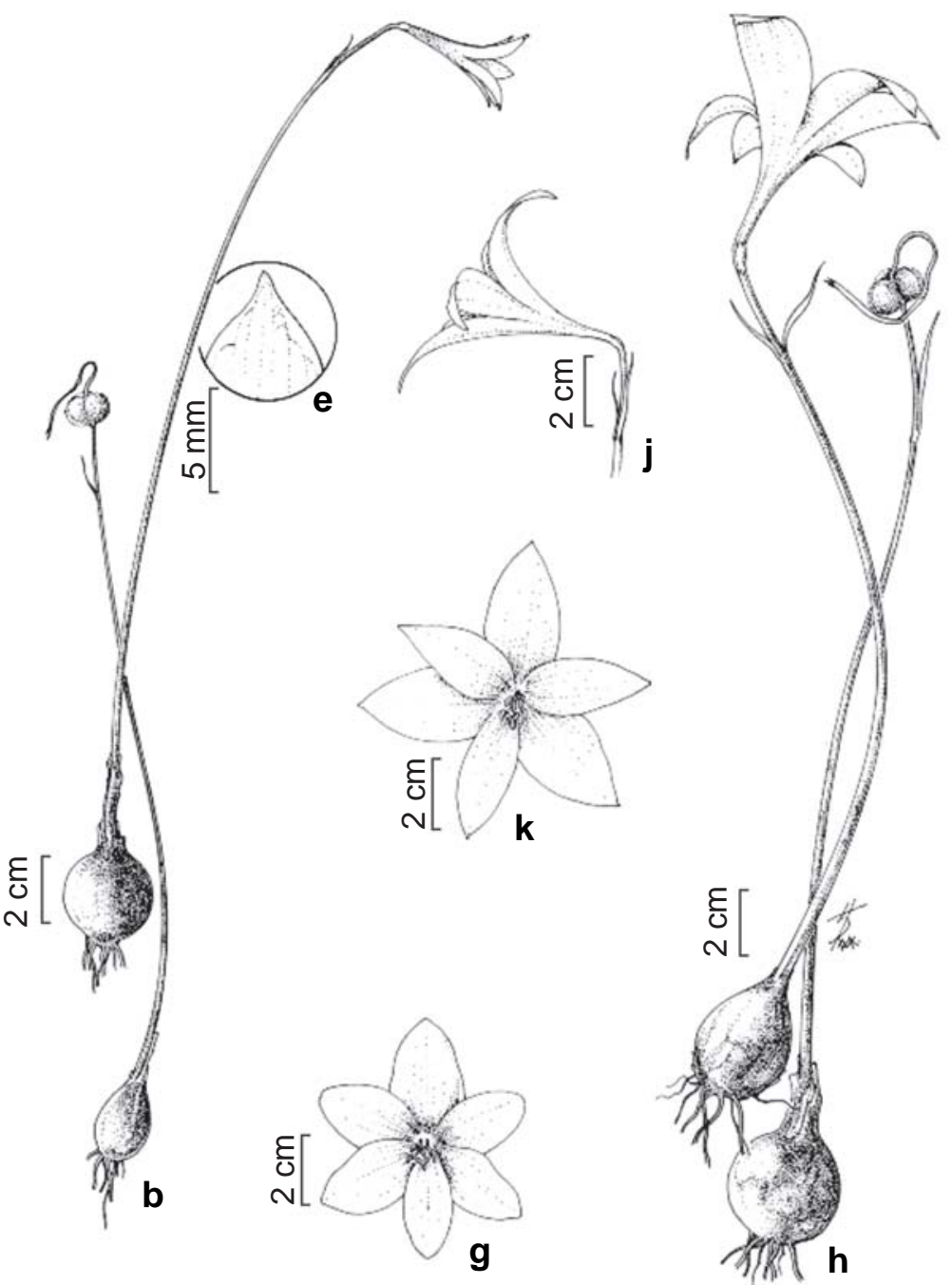

Figura 4 - Habranthus - a-b. H. itaobinus Rav. (Alves-Araújo 36) - a-b. hábito; c. flor em vista lateral; d. flor em vista frontal; e. detalhe do ápice da tépala superior externa. f-g. H. robustus Herb. ex Sweet. (AlvesAraújo 43) - f. flor em vista lateral; g. flor em vista frontal. h-1. H. sylvaticus Herb. (Alves-Araújo 30) - h-1. hábito; j. flor em vista lateral; k. flor em vista frontal; 1. estigma trífido.

Figure 4 - Habranthus - a-b. H. itaobinus Rav. (Alves-Araújo 36) - a-b. habit; c. flower, lateral view; d. flower, frontal view; e. outer superior tepal, detail of the apex. f-g. H. robustus Herb. ex Sweet. (AlvesAraújo 43) - f. flower, lateral view; g. flower, frontal view. h-1. H. sylvaticus Herb. (Alves-Araújo 30) - h-1. habit; j. flower, lateral view; k. flower, frontal view; 1 . trifid stigma.

dialistêmones, filetes alvos na região mediana a vermelhos na região apical, base verde, anteras amarelas, pólen amarelo-intenso; ovário 6-10 mm compr., ínfero, vermelho a verde-claro, 58-60 óvulos por lóculo, estilete $8,7-10,1 \mathrm{~cm}$ compr., alvo na região mediana a vermelho na região apical, base verde, estigma trilobado, vermelho. Frutos depresso-globosos, verdes, 3-sulcados. Sementes aladas, arredondadas a deltóides, negras.
Material examinado selecionado: BRASIL. BAHIA: Abaíra, 09.I.2006, fl., T. Nunes et al. 1512 (HUEFS); Andaraí, Serra de Andaraí, 30.X.1978, fr., G. Martinelli et al. 5451 (RB); Ilhéus, 14.X.1981, fl., J. Hage \& H. Brito 1456 (CEPEC); Itapebi, 14.VIII.1971, fl., T. Santos 1822 (CEPEC); Lençóis, 22.XII.1981, fl., G Lewis et al. 939 (CEPEC); Santa Cruz Cabrália, 9.II.1984, fl., E. Santos 247 (CEPEC); PERNAMBUCO: Bezerros, 17.XI.2005, fl., A. Alves-Araújo et al. 40 (RB, UFP); Recife, Engenho Uchôa, 11.II.1996, fl. e fr., C. Eugênio 21 (IPA); São Lourenço da Mata, Estação Ecológica 
de Tapacurá, 18.XII.2005, fl., A. Alves-Araújo et al. 49 (UFP); Quipapá, Engenho Brejinho, 2.X.1980, fl., I. Pontual 1735 (PEUFR).

Hippeastrum puniceum distribui-se por todo o Brasil e Américas, ocupando várias formações vegetais e ambientes, além de apresentar grande variação morfológica das folhas e da coloração das flores (Dutilh 2005). Foi observada grande produção de bulbilhos laterais, com florescimento entre os meses de novembro e dezembro e botões florais em diferentes estádios de desenvolvimento simultaneamente. Espécie de fácil cultivo e comum em jardins de todo o território brasileiro, mas não foi observada sua floração sob cultivo. Caracteriza-se pela curvatura do pedicelo em sua porção apical, conferindo ao ovário uma posição perpendicular em relação ao escapo e diferindo de $H$. stylosum pelos filetes e estilete ascendentes formando um ângulo de $90^{\circ}$.

7. Hippeastrum solandriflorum (Lindl.) Herb. An Appendix, Bot. Reg.: 31. 1821.

Fig. 5d, 6a

Bulbo ovado a orbicular; colo $1-2 \mathrm{~cm}$ compr. Folhas (32-)45(-58) × (2-)3(4) cm, decíduas, dísticas, eretas, ensiformes, canaliculadas, nervura central não conspícua, verde-claras em ambas as faces, ápice agudo, margens inteiras, retas. Inflorescência 1-2flora, umbeliforme; escapo 25-63 cm compr., fistuloso, brácteas 3,5-5,7 cm compr., espatáceas, hialinas. Flores declinadas, infundibuliformes, hipanto 7,6-9 cm compr., pedicelo 2,5-5,5 cm compr., paraperigônio ausente; tépalas-6, alvas a creme-amareladas, tépala externa superior $(7,5-) 9,5 \times(2,8-) 5 \mathrm{~cm}$, tépalas externas laterais $(7,5-) 9,3 \times(2,5-) 3 \mathrm{~cm}$, tépala interna inferior $(7,2-) 11 \times(2,5-) 5 \mathrm{~cm}$, tépalas internas laterais $(6,5-) 9,2 \times(1,8-) 3 \mathrm{~cm}$; estames isodínamos, eretos, 5,8-8,3 cm compr., dialistêmones, filetes alvos a creme-amarelados, pólen amarelo-intenso; ovário 8-13 mm compr., verde-claro; estilete 15,8-17,5 cm compr., creme-amarelado, estigma trilobado. Frutos e sementes não observados. Material examinado selecionado: BRASIL. BAHIA: Abaíra, 25.II.1992, fl., P. Sano s.n. (HUEFS 50929, BHCB); Mucugê, 25.XI.2000, fl., A. Conceição 898
(SPF);Palmeiras, 21.X.1999, fl.,A. Conceição 616(SPF); Piatã, 26.XII.1992, fl., R. Harleyetal. s.n. (HUEFS 50930, SPF 50421); CEARÁ:Aiuaba, 11.XII.1997, fl., L. LimaVerde et al. 855 (HUEFS); PERNAMBUCO: Petrolina, 2-9.I.1961, fl., A. Lima s.n. (RB 113572).

Hippeastrum solandriflorum possui ampla distribuição no Brasil, nas Regiões Nordeste e Centro-Oeste, ocorrendo ainda na Colômbia, Guianas e Venezuela (Ravenna 1970).

Ravenna (1970) descreveu Amaryllis araripina Ravenna a partir de espécimes coletados em Araripina - Pernambuco. Meerow et al. (1997) propuseram a transferência de A. araripina para Hippeastrum. Neste trabalho, visando maior segurança na validade nomenclatural, optou-se por considerar Hippeastrum araripinum (Ravenna) Meerow sinônimo de $H$. solandriflorum. Contudo, o material-tipo depositado na coleção particular do P. Ravenna não foi examinado.

Hippeastrum solandriflorum caracterizase pelo comprimento do hipanto, que pode alcançar $9 \mathrm{~cm}$, ausência de paraperigônio e por ser a única espécie do gênero no nordeste com flores completamente alvas a cremeamareladas.

8. Hippeastrum stylosum Herb., Bot. Mag.49:2278. 1822. Fig. 1g, 5e-h, 6a

Bulbo subterrâneo a parcialmente exposto, ovado a orbicular; colo $9-50 \mathrm{~mm}$ compr. Folhas $(36,1-) 52(-64,4) \times(2,1-) 3,6$ $(-5,9) \mathrm{cm}$, decíduas, dísticas, eretas a levemente prostradas, ensiformes, fortemente canaliculadas, nervura central não conspícua, verde-claras a escuras em ambas as faces, base vinácea, ápice agudo, margens inteiras, retas. Inflorescência 2-7-flora, umbeliforme; escapo 43,5-97 cm compr., verde-escuro a vináceo, base vinácea; brácteas 4-7,2 cm compr., espatáceas, verdes, róseas a vináceas. Flores declinadas, infundibuliformes, hipanto 1-2 cm compr., paraperigônio fimbriado, pedicelo 2,35,8 cm compr.; tépalas- 6 , magenta a vermelhovivo, por vezes com raio longitudinal verde ao longo da tépala, verdes, magentas ou vermelhas 

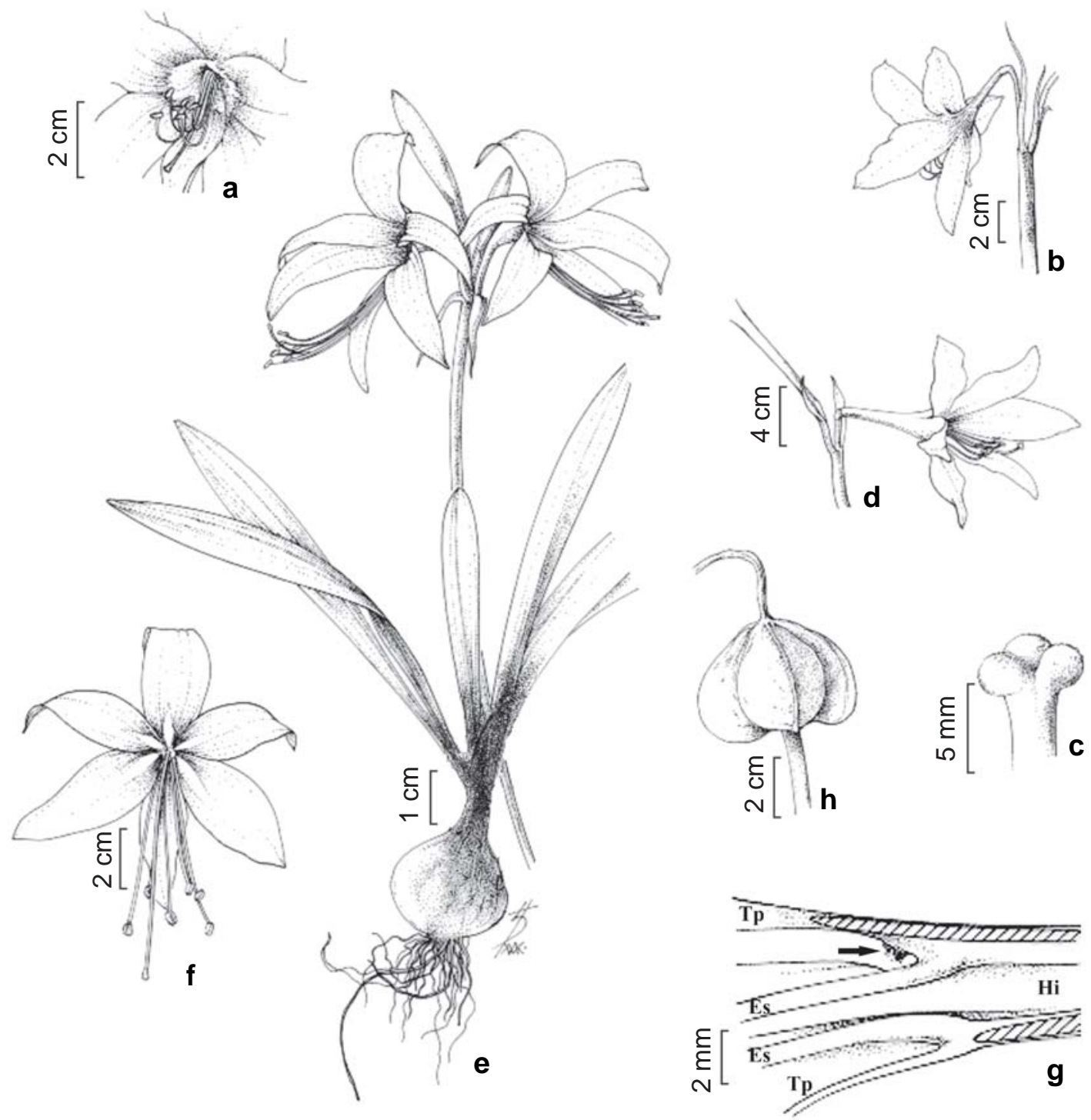

Figura 5 - Hippeastrum - a-c. H. puniceum (Lam.) Kuntze (Alves-Araújo 40) - a. flor em vista frontal; b. flor em vista lateral; c. estigma trilobado. d. H. solandriflorum Herb. (Conceição 898) - d. flor em vista lateral. e-h. H. stylosum Herb. (Alves-Araújo 21) - e. hábito; f. flor em vista frontal; g. flor em seção longitudinal evidenciando o detalhe do paraperigônio fimbriado (seta); h. fruto. Es=estame; Hi=hipanto;Tp=tépala.

Figure 5 - Hippeastrum - a-c. H. puniceum (Lam.) Kuntze (Alves-Araújo 40) - a. flower, frontal view; b. flower, lateral view; c. trilobate stigma. d. H. solandriflorum Herb. (Conceição 898) - d. flower, lateral view. e-h. H. stylosum Herb. (Alves-Araújo 21 ) - e. habit; f. flower, frontal view; g. flower, longitudinal section showing the fimbriated corona (arrow); h. fruit. Es=stamen; Hi=hypanthium; $\mathrm{Tp}=$ tepal.

na base, ausência de anel mediano, tépala externa superior $(6,1-) 8,1(-9) \times(1,5-) 2,7(-3,3)$ $\mathrm{cm}$, tépalas externas laterais $(6-) 7,9(-9) \times$ $(1,4-) 2,8(-3,6) \mathrm{cm}$, tépala interna inferior (6-) $7,8(-8,9) \times(1-) 1,7(-2,4) \mathrm{cm}$, tépalas internas laterais $(6,2-) 7,8(-9) \times(1,2-) 1,7(2,5) \mathrm{cm}$; estames isodínamos, eretos, 7-10,2 cm compr., dialistêmone, filetes magenta a vermelhos, máculas vináceas, anteras creme com faixas vináceas, pólen amarelo-intenso; ovário 9-10 mm compr., verde-claro, 56-60 óvulos por lóculo; estilete 8-13,5 cm compr., magenta a vermelho, base branca, estigma trilobado, vermelho a vináceo. Frutos depresso-globosos, verdes, 3-sulcados. Sementes aladas, arredondadas a deltóides, negras. 
Material examinadoselecionado: BRASIL.ALAGOAS: Piaçabuçu, Ponta de Terra, 17.XI.1987, fl. efr., D. Araújo et al. 1956 (MAC); BAHIA: Banzae, 20.X.2002, fl., $C$. Correia et al. 204 (HUEFS); Cravolândia, 15.X.1975, fl., J. Hage 105 (CEPEC); Feira de Santana, 13.XI.1986, fl., L. Queiroz \& N. Lemos s.n. (HUEFS 6714); Ipuaçú, IX.1998, fl., Grupo Pedra do Cavalo [Scardino et al.] 730 (CEPEC); Jequié, 22.IX.1965, fl., A. Duarte \& E. Pereira 9315 (RB); Mucugê, 9.XI.2004, fl., C. Costa \& J. Costa 127 (HUEFS); Nova Itarana, 30.VIII.1996, fl., R. Harley \& A. Giulietti 28211 (HUEFS); Santa Teresinha, 13.IX.1997,fl.,E. Miranda etal. 10(HUEFS); CEARÁ: Cedro, V.1912, fl., Löfgren 786 (R); MARANHÃO: SãoLuís, 22-23.X.1982, fl., K. Yamamoto et al. s.n. (UEC 14257); PARAIÍBA: Areia, Mata do PauFerro, 12.I.1981, fl., V. Fevereiro et al. s.n. (JPB 544); Rio Tinto, 8.III.1990, fl., L. Félix \& E. Santana 2839(JPB); Serraria, 28.XI.1942, fl., L. Xavier s.n. (JPB 1192); PERNAMBUCO: Agrestina, Pedra do Careca, 21.III.2005,fl.,A.Alves-Araújo et al. 21 (SPF,UEC,UFP); Bezerros, FazendaAntônio Bezerra, 26.XII.2005, fl., A. Alves-Araújo et al. 51 (HUEFS, R, RB, UFP); Bonito, Reserva Municipal de Bonito, 19.I.2005, fl., A. AlvesAraújo et al. 18(UEC, UFP); Brejo da Madre de Deus, 3.III.2005, fl. efr., E. Borba etal. 2188(HUEFS); Buíque, Parque Nacional do Catimbau, 30.VII.2005, fl., A. AlvesAraújo et al. 32 (UFP); Cabo de Santo Agostinho, Praia de Calhetas (Parque Metropolitano Armando Holanda Cavalcanti), 11.XII.2005, fl., A. Alves-Araújo et al. 47 (UFP, RB); Caruaru, Brejo dos Cavalos, 9.IV.1996, fr., $M$. Tschá 745 (PEUFR); Pesqueira, Serra do Ororubá, 3.III.1996, fl., M. Correia 430 (IPA); Pombos, Serra das Russas, 16.XI.2005, fl.,A.Alves-Araújo et al. 39(HUEFS, RB, UFP); Recife, Engenho Uchôa, 6.X.1996, fl., $C$. Eugênio 37 (IPA); São Lourenço da Mata, Estação Ecológica de Tapacurá, 17.I.2005, fl.,A. Alves-Araújo et al. 17 (UEC, UFP, SPF); São Vicente Férrer, 8.I.1996, fl., L. Silva et al. 118 (PEUFR); Taquaritinga do Norte, sítio Cafundó, 28.XII.1972, fl., D. Andrade-Lima 7131 (IPA); Vitória de Santo Antão, Sítio do Torto, 9.XII.1981, fl., L. Mesquita s.n. (IPA 28238); RIO GRANDE DO NORTE: Timbau do Sul, Santuário Ecológico de Pipa, 29.V.2006, fl.,A. Alves-Araújo et al. 176 (flor em cultivo); SERGIPE: Neópolis, 6.II.1975, fl.,A. Barreto s.n. (ASE 298); Tobias Barreto, 6.X.1981, fr., E. Carneiro 111 (ASE).

Hippeastrum stylosum tem ampla distribuição no nordeste, ocupando desde paredões rochosos costeiros, restinga, Mata Atlântica até afloramentos rochosos na caatinga. Ocorre em áreas abertas, sob arbustos, ilhas de solo em "inselbergs" e gretas de rochas. Em diferentes populações acompanhadas, foi observada uma grande variação morfológica com relação à coloração das tépalas, presença ou não de faixa verde longitudinal nas mesmas, tamanho das flores, número de flores por escapo e coloração das folhas. Foi constatada grande produção de bulbilhos laterais e o florescimento em condições naturais entre novembro a janeiro, com botões em diferentes estádios de desenvolvimento simultaneamente. A floração de alguns indivíduos em cultivo ocorreu após cinco meses de estresse hídrico. É facilmente reconhecida pelos estames e estilete exsertos. Quando comparada a $H$. puniceum, $H$. stylosum não possui anel alvo a creme na região mediana das tépalas, tampouco as tépalas superiores são fortemente reflexas.

\section{Hymenocallis Salisb.}

Folhas perenes ou anuais, sésseis a pseudopecioladas. Escapo biconvexo, sólido; brácteas da inflorescência-2, livres. Inflorescência multiflora. Flores geralmente sésseis, odoríferas, antese vespertino-noturna, actinomorfas. Estames-6, eretos, conatos na base formando a corona estaminal. Ovário ínfero; estigma capitado.

9. Hymenocallis littoralis Salisb., Trans. Hort. Soc. London 1: 338. 1812. Fig. 1h, 6b, 7a-b

Bulbo oblato a orbicular; colo 3-3,5 cm compr. Folhas $(67,3-) 80,3(-91) \times(5-) 6,1(-6,5)$ $\mathrm{cm}$, perenes, dísticas, eretas, sésseis, canaliculadas, nervura central proeminente, verde-brilhantes em ambas as faces, ápice agudo, margens inteiras, retas. Inflorescência 13-17-flora, umbeliforme; escapo 59-62 cm compr., espiralado em seu eixo, verde-claro; brácteas 7,6-8 cm compr., espatáceas, verdes. Flores eretas, infundibuliformes, hipanto (20,2-)21,3 $(-22,1) \mathrm{cm}$ compr., sésseis; tépalas-6, alvas, bases verdes, deflexas, isomorfas, tépalas $(12,5-) 12,8(-13,1) \mathrm{cm} \times(4-) 5 \mathrm{~mm}$; estames isodínamos, 9,9-10,2 cm compr., filetes verdes, corona estaminal 3-3,1 cm compr., alva; anteras translúcidas, pólen amarelo; ovário 1,51,8 cm compr., verde, 5-6-óvulos por lóculo; 


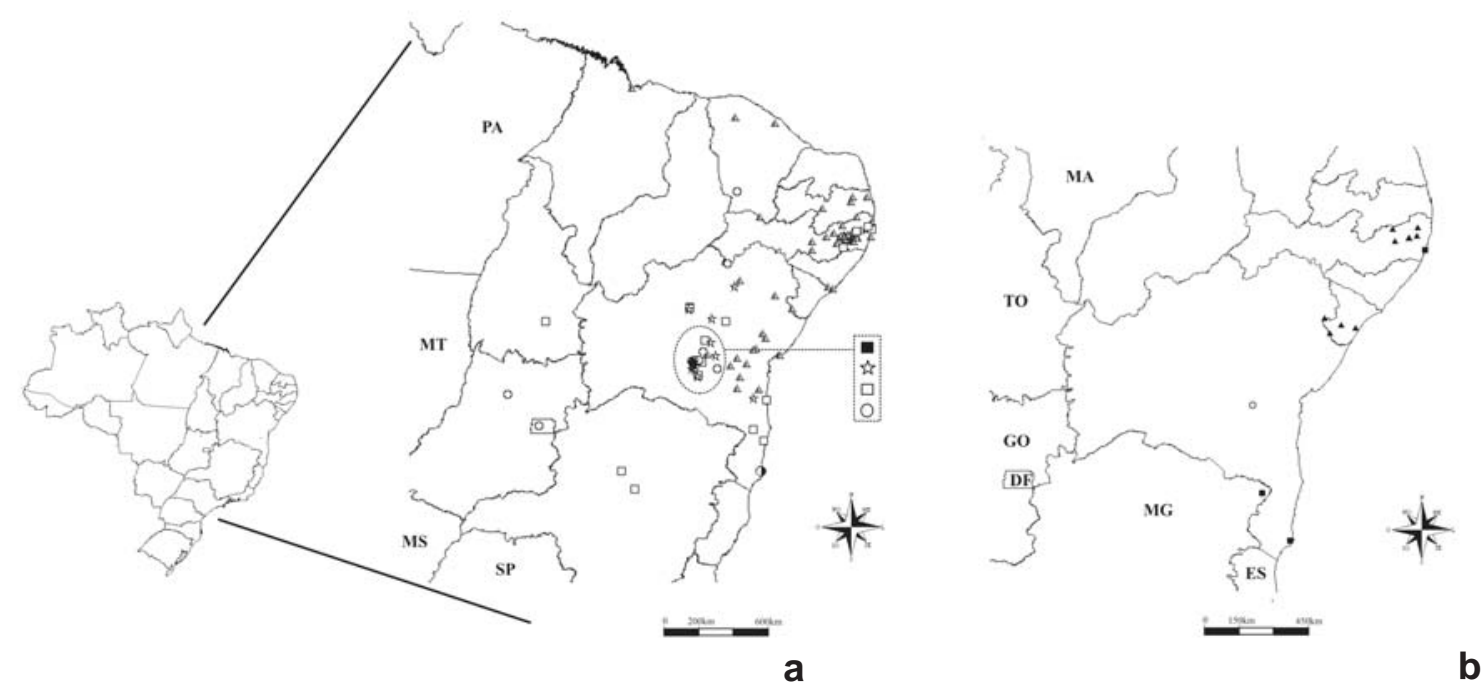

Figura 6 - Mapas de distribuição das espécies de Amaryllidaceae s.s. e Alliaceae s.s. no nordeste brasileiro - a. Hippeastrum Herb.: $\triangle$ H. stylosum Herb.; $\square$ H. puniceum (Lam.) Kuntze; $\bigcirc$ H. solandriflorum Herb.; ‘े H. glaucescens Herb.; - H. reticulatum Herb. b. Hymenocallis littoralis Salisb.; $\boldsymbol{\Delta}$ Nothoscordum pernambucanum Rav.; O Nothoscordum bahiense Rav. (Alliaceae s.s.).

Figure 6 - Distribution of Amaryllidaceae s.s. and Alliaceae s.s. species at northeastern Brasil - a. Hippeastrum Herb.: $\triangle$ H. stylosum Herb.; $\square$ H. puniceum (Lam.) Kuntze; $\bigcirc$ H. solandriflorum Herb.; is H. glaucescens Herb.; $H$. reticulatum Herb. b. Hymenocallis littoralis Salisb.; $\boldsymbol{\Delta}$ Nothoscordum pernambucanum Rav.; O Nothoscordum bahiense Rav. (Alliaceae s.s.).

estilete 31,2-34,8 cm compr., alvo, base verde, estigma alvo. Frutos e sementes não observados.

Material examinado: BRASIL. PERNAMBUCO: Ipojuca, Praia de Porto de Galinhas, flor em cultivo, 18.I.2006, fl. e fr., A. Alves-Araújo et al. 54 (EAC, HUEFS, MAC, UFP).

Hymenocallis littoralis distribui-se ao longo de todo litoral brasileiro, além de ocorrer na América do Norte e América do Sul (Traub 1962). O único espécime disponível para análise foi mantido em cultivo sob condições não controladas, onde foi possível a observação da produção de bulbilhos laterais. A floração sob cultivo foi observada em janeiro, com produção de flores odoríferas, antese vespertina e botões simultaneamente em diferentes estádios de desenvolvimento. É facilmente reconhecida, dentre os táxons examinados, pela presença de corona estaminal membranácea típica da tribo Hymenocallideae e dos filetes livres exsertos. O termo corona estaminal é citado por Meerow \& Snijman (1998) como copo estaminal, porém trata-se da mesma estrutura floral.

\section{Nothoscordum Kunth}

Folhas perenes ou anuais, sésseis. Escapo cilíndrico, sólido; brácteas da inflorescência geralmente 2, livres ou com base concrescida. Inflorescência uni a multiflora. Flores pediceladas, odoríferas e antese diurna, actinomorfas. Estames6, eretos. Ovário súpero; estigma capitado.

\section{Nothoscordum pernambucanum} Ravenna, Onira Bot. Leafl. 7(7): 44. 2002.

Fig. 1i, 6b, 7c-f

Bulbo obovado a ovado; colo 6-24 mm compr. Folhas $(14,8-) 18,1(-22,2) \mathrm{cm} \times 3(-4) \mathrm{mm}$, decíduas, dísticas, eretas, ensiformes, nervura central não conspícua, verde-claro em ambas as faces, ápice agudo, margens inteiras, retas. Inflorescência 5-9-flora, umbeliforme; escapo 14,8-22,7 cm compr., verde; brácteas 4-7 mm compr., espatáceas, base concrescida, translúcidas. Flores eretas, crateriformes, pedicelo 1,5-3,5 cm compr.; tépalas-6, alvas com nervuras centrais vináceas a enegrecidas, com base verde, discretamente concrescidas na base, isomorfas, tépalas $(5-) 6(-7) \times 2(-3) \mathrm{mm}$; estames isodínamos, 
eretos, (4-)5 mm compr., dialistêmone, filetes alvos, base verde, anteras amarelas, pólen amarelo-intenso; ovário 1-2 mm compr., verde, 2 óvulos por lóculo; estilete 4-5 mm compr., alvo, estigma alvo. Frutos 3-sulcados, verdes.

Sementes ovóides, negras.

Material examinado: BRASIL. PERNAMBUCO: Carpina, 26.III.1987, fl. e fr., V. Lima \& A. Rita s.n. (IPA 50870); Caruaru, 7.V.1966, fl. e fr., E. Tenório 116 (IPA); Gravatá, VII.1926, fl. e fr., B. Pickel s.n. (IPA 3541); 20.VII.1997, fl., M. Guerra \& L. Félix 1413 (UFP-Holótipo); 30.III.2006, fl., A. Alves-Araújo et al. 76 (EAC, HUEFS, UFP); São Caetano, 24.IV.1966, fl. e fr., D. Andrade-Lima 4530 (IPA); Taquaritinga do Norte, 18.IV.1997, fl. e fr., s.col. 1204 (IPA); Vitória de Santo Antão, Engenho Pombal, 8.VIII.1998, fl. e fr., A. Laurênio et al. 1174 (PEUFR); SERGIPE: Lagarto, 7.V.1982, fl., E. Carneiro 367 (ASE, IPA); Poço Verde, 6.V.1982, fl., G. Viana 433 (ASE); São Cristóvão, 25.IV.1984, fl., G. Viana 932 (ASE); Tobias Barreto, 25.VIII.1983, fl., E. Gomes 344 (ASE).

Nothoscordum pernambucanum constitui o registro com distribuição mais setentrional para o gênero no Brasil (Ravenna 2002), ocorrendo nos estados de Pernambuco e Sergipe.

Em seu primeiro registro na região, a espécie foi tratada como Nothoscordum pulchellum Kunth por Guerra \& Félix (2000), que a utilizou em estudo citogenético. Ravenna (2002) a reconheceu como táxon distinto do anterior, principalmente, pela forma do ovário e número de óvulos por lóculo. Os espécimes sob condições de rega contínua apresentam grande produção de bulbilhos e intenso florescimento ao longo do ano.

Os táxons abaixo relacionados não foram encontrados durante as excursões de coleta, porém, estão incluídos dentre as espécies nativas do Nordeste.

11. Griffinia alba Preuss \& Meerow, Novon 10: 230. 2000.

Fig. 3a

Folhas $40 \mathrm{~cm}$ compr., perenes, ovadas a elípticas, pseudopecíolo $30 \mathrm{~cm}$ compr. Escapo 35-38 cm compr. Inflorescência 16-17-flora. Flores declinadas, infundibuliformes, hipanto 1,3-1,8 cm compr., alvas. Estames-6, heterodínamos. Ovário ca. $1 \mathrm{~cm}$ compr.
A espécie é conhecida apenas pelo tipo, tendo sido coletada no ano de 1936 em Tapera, atualmente, município de São Lourenço da Mata, Pernambuco (Preuss \& Meerow 2000). A presença de populações naturais não foi constatada no local referido na etiqueta do material-tipo assim como nos arredores, tampouco amostras em coleções botânicas foram localizadas nos acervos consultados. O material-tipo não foi examinado (US). Esta espécie constitui juntamente com G. cordata Preuss \& Meerow e G. leucantha Preuss \& Meerow, os táxons do subg. Griffinia que possuem flores completamente alvas (Preuss \& Meerow 2000, 2001b).

12. Griffinia arifolia Ravenna, Onira Bot. Leafl. 4(5): 19-20. 2000.

Fig. 3a

Folhas $37 \mathrm{~cm}$ compr., perenes, sagitadas, pseudopecíolo ca. $35 \mathrm{~cm}$ compr. Escapo 16$16,5 \mathrm{~cm}$ compr. Inflorescência 11-flora. Flores patentes, infundibuliformes, hipanto 2,2-2,8 mm compr., lilás. Estames-6, heterodínamos. Ovário 3-4 mm compr.

Conhecida apenas pelo material-tipo, coletado no município de Alcobaça, Bahia. Distingue-se das demais espécies pelas folhas longo-pseudopecioladas e folha sagitada semelhante ao do gênero Arum (Araceae) (Ravenna 2000b).

13. Griffinia itambensis Ravenna, Pl. Life 30: 70.1974.

Fig. 3a

Folhas 12-25 cm compr., perenes, lanceoladas, pseudopecioladas. Escapo ca. 19 cm compr. Inflorescência 7-11-flora. Flores declinadas, infundibuliformes, hipanto $1,5 \mathrm{~mm}$ compr., lilás. Estames-5-6, heterodínamos.

Griffinia itambensis é conhecida apenas para a região do sul da Bahia e Minas Gerais. Pode ser reconhecida, segundo Preuss (1999), por suas folhas lanceoladas e sem máculas alvas e flores diminutas (as menores do gênero). De acordo com Preuss (1999), esta espécie provavelmente trata-se de uma variedade de Griffinia espiritensis. 


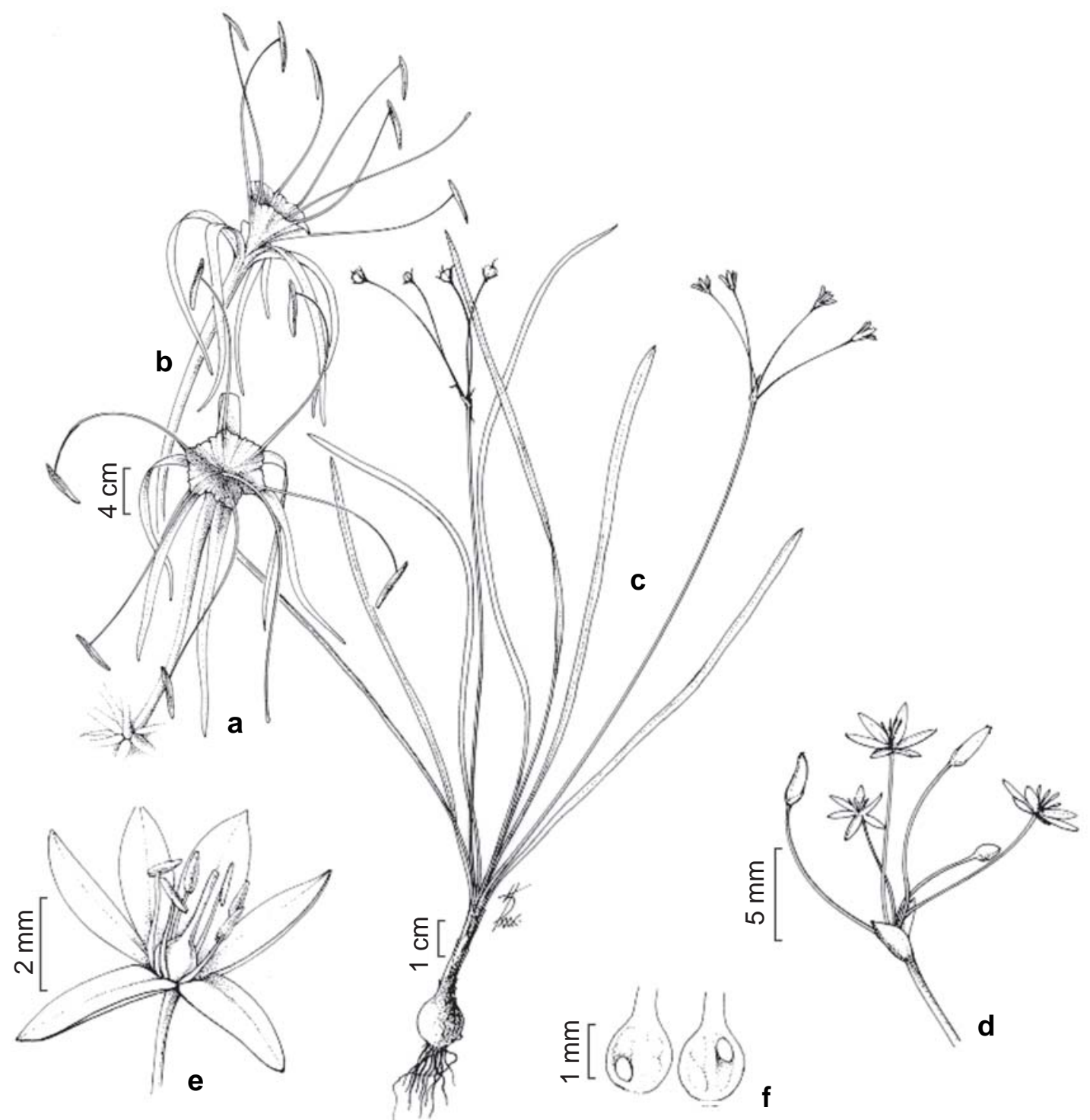

Figura 7 - a-b. Hymenocallis littoralis Salisb. (Alves-Araújo 54) - a. flor em vista frontal; b. flor em vista lateral. c-f. Nothoscordum pernambucanum Rav. (AlvesAraújo 76) - c. hábito; d. detalhe da inflorescência; e. detalhe da flor; f. ovário em seção longitudinal.

Figure 7 - a-b. Hymenocallis littoralis Salisb. (Alves-Araújo 54) - a. flower, frontal view; b. flower, lateral view. c-f. Nothoscordum pernambucanum Rav. (AlvesAraújo 76) - c. habit; d. inflorescence, detail; e. flower, detail; f. ovary, longitudinal section.

14. Griffinia intermedia Lindl. Bot. Reg. 7: 990. 1826.

Folhas perenes, ovado-elípticas, pseudopecioladas. Escapo ca. $30 \mathrm{~cm}$ compr. Inflorescência 6-10-flora. Flores declinadas, infundibuliformes, lilás. Estames-6, heterodínamos.

Possui distribuição disjunta, nos estados da Bahia e do Rio de Janeiro
(Preuss 1999). Caracteriza-se pelo comprimento do escapo (ca. $30 \mathrm{~cm}$ ) e o número de flores (6-10-flora) associados dentre as espécies de Griffinia. Entretanto, Preuss (1999) não quantifica tampouco qualifica acuradamente estes caracteres a fim de esclarecer as identidades dos táxons. 
15. Griffinia parviflora Ker Gawler, Bot. Reg. 6: 511. 1821.

Fig. 3a

Folhas 18-29 cm compr., perenes, ovadas, pseudopecioladas. Escapo 20-25 cm compr., com pigmentação vermelha na base. Inflorescência 10-15-flora. Flores declinadas, infundibuliformes, hipanto ca. $3 \mathrm{~mm}$ compr., lilás. Estames-6, heterodínamos.

Espécie com distribuição nos estados da Bahia e Espírito Santo, ocorrendo principalmente no sub-bosque da Mata Atlântica. Diferencia-se das demais espécies do gênero pela coloração avermelhada da base do pseudopecíolo e do escapo (Preuss 1999).

16. Griffinia nocturna Ravenna, $\mathrm{Pl}$. Life 25 : 63. 1969.

Fig. 3a

Folhas $40-50 \mathrm{~cm}$ compr., anuais, oblanceoladas, sésseis. Escapo 14-35 cm compr. Inflorescência 3-4-flora. Flores declinadoascendentes, subsésseis, infundibuliformes, hipanto 1-5 cm compr., alvas. Estames-6, heterodínamos.

Griffinia nocturna juntamente com $G$. gardneriana ocupam áreas mais secas das regiões Centro-Oeste e Nordeste. A primeira ocorre, geralmente, associada ao Cerrado, enquanto a segunda, à Caatinga (Preuss 1999). Diferenciam-se pelo comprimento do hipanto $(1-5 \mathrm{~cm})$ e as flores subsésseis presentes em G. nocturna.

17. Habranthus bahiensis Ravenna, Onira Bot. Leafl.1(8): 53. 1988.

Fig. $3 b$

Folhas ca. 12,5 cm compr., perenes, filiformes. Escapo 10,5-15 cm compr. Flores infundibuliformes, hipanto 3-5 $\mathrm{mm}$ compr., paraperigônio setiforme. Estames tetradínamos. Estilete 3,9-5,9 cm compr. Ovário 2-4 mm compr., estigma trilobado.

Esta espécie foi coletada apenas na Bahia (Dutilh 2003). Segundo Oliveira (2006), é endêmica de Morro do Chapéu, no norte da Cadeia do Espinhaço, e distingue-se das demais espécies principalmente pelas folhas filiformes, hipanto curto (3-5 $\mathrm{mm}$ compr.) e paraperigônio setiforme.

18. Habranthus datensis Ravenna, Onira Bot. Leafl. 3(16): 58. 1999.

Fig. $3 b$

Folhas ca. $5 \mathrm{~cm}$ compr., perenes, ensiformes. Escapo 6-16 cm compr. Flores infundibuliformes, zigomorfas, hipanto 1-4 mm compr., paraperigônio fimbriado. Estames tetradínamos. Estilete 2,5-4,1 cm compr. Ovário 3-8 mm compr., estigma trífido.

Espécie registrada para os estados da Bahia e Minas Gerais, podendo ser reconhecida principalmente pela presença do paraperigônio fimbriado associada aos estames em quatro alturas distintas (Oliveira 2006).

19. Habranthus aff. itaobinus Ravenna, Onira Bot. Leafl., 3(16): 56. $1999 . \quad$ Fig. 3b

Folhas ca. $7 \mathrm{~cm}$ compr., perenes, ensiformes. Escapo 9,8-16,3 cm compr. Flores infundibuliformes, hipanto $2-5 \mathrm{~mm}$ compr., paraperigônio reduzido a calosidades. Estames tridínamos. Estilete 1,7-2,4 cm compr. Ovário 3-6 mm compr., estigma trilobado.

De acordo com Oliveira (2006), este táxon é endêmico da região de Rio de Contas, Bahia. Os principais caracteres diagnósticos deste táxon em relação aos demais são as flores menores, hipanto relativamente mais largo e, principalmente, a venação reticulada das tépalas, que é bastante evidente devido à coloração distinta das áreas intervenais. Segundo Oliveira (2006), pode ser considerada uma nova espécie para a ciência.

20. Hippeastrum glaucescens Herb., Amaryllidaceae: 139. $1837 . \quad$ Fig. 6a

Folhas anuais, loriformes a falcadas. Inflorescência biflora. Flores horizontais a ascendentes, campanuladas, hipanto 1,6-2,2 cm compr., paraperigônio denteado. Ovário 12,316 mm compr., estigma trilobado.

Distribui-se desde os estados da Bahia e Goiás, sul do Brasil à Argentina, ocupando 
áreas abertas e pedregosas (Dutilh 2005). Apresenta flores campanuladas, alaranjadas a vermelhas com reticulados mais escuros no terço superior das tépalas, além do estigma trilobado e paraperigônio denteado como caracteres distintivos entre as espécies analisadas.

21. Hippeastrum reticulatum Herb., Bot. Mag.: 2475. 1824.

Fig. 6a

Folhas anuais, lanceoladas. Inflorescência 2-5-flora. Flores horizontais a ascendentes, campanuladas, hipanto 1,3-2,5 cm compr., paraperigônio ausente. Estigma capitado.

Conhecida para os estados do Espírito Santo, São Paulo e Santa Catarina, é citada pela primeira vez citada para o Nordeste, a partir de dois espécimens coletados no município de Alcobaça, BA, e depositados no IPA e R. Distingue-se das demais espécies de Hippeastrum pela ausência de paraperigônio (caráter compartilhado com H. solandriflorum), presença de estigma capitado, paredes internas do fruto alaranjadas e sementes globosas. Além disso, pode apresentar uma linha alva ao longo da folha.

22. Nothoscordum bahiense Ravenna, Onira Bot. Leafl. 3(7): 19-21. $1991 . \quad$ Fig. 6b

Folhas anuais, ensiformes. Inflorescência 3-6-flora. Flores eretas, craterifomes. Estames isodínamos. Estilete ca. $3 \mathrm{~mm}$ compr. Ovário 1 mm compr., 1 óvulo/lóculo.

Está restrita ao estado da Bahia. Assemelhase a $N$. pernambucanum, porém possui apenas um óvulo por lóculo do ovário (Ravenna 1991).

\section{Agradecimentos}

Ao $\mathrm{CNPq}$ pela concessão da bolsa ao primeiro autor. Aos Professores Dr. Marcelo Guerra e Eduardo Raduenz, pela disponibilidade de material botânico. Às Dras. Ana Cláudia Araújo e Gardene Sousa pelas sugestões para este trabalho. Aos revisores ad hoc pelas sugestões. E, por fim, aos integrantes do Laboratório MTV/UFPE.

\section{REFERÊNCIAS BIBLIOGRÁFICAS}

APG (Angiosperm Phylogeny Group). 2003. An update of the angiosperm phylogeny group classification for the orders and families of flowering plants: APG II. Botanical Journal of the Linnean Society 141: 399-436.

Coutinho, L. M. 2006. O conceito de bioma. Acta Botanica Brasilica 20(1):13-23.

Cronquist, A. A. 1981. An integrated system of classification of flowering plants. New York Botanical Garden, New York, USA.

Dutilh, J. H. A. 2003. Revisão manuscrita da família Alliaceae, Amaryllidaceae. APNE-CNIP, Recife, Pernambuco.

Dutilh, J. H. A. 2005. Amaryllidaceae. In: Wanderley, M.G.L.; Shepherd, G. J.; Melhem, T. S.; Martins, S. E.; Kirizawa, M. \& Giulietti, A. M. (eds.). Flora fanerogâmica do estado de São Paulo. São Paulo. Pp. 244-256.

Dutilh, J. H. A. 2006. Alliaceae, Amaryllidaceae. In: Barbosa, M. R. V.; Sothers, C.; Mayo, S.; Gamarra-Rojas, C. F. L. \& Mesquita, A. C. (eds.). Checklist das plantas do nordeste brasileiro: Angiospermas e Gymnospermas. Brasília. Pp. 26-27.

Font Quer, P. 1989. Diccionario de botánica. Editorial Labor, Barcelona.

Guerra, M. \& Félix, L. P. 2000. O cariótipo de Nothoscordum pulchellum (Alliaceae) com ênfase na heterocromatina e nos sítios de DNAr. Boletim da Sociedade Argentina de Botânica 35(3-4): 283-289.

Harris, J. G. \& Harris, M. W. 1994. Plant identification terminology: an illustrated glossary. Spring Lake Publishing, Spring Lake, Utah.

Holmgren, P. K. \& Holmgren, N. H. 2006 onwards (continuously updated). Index herbariorum. New York Botanical Garden. <http://sciweb.nybg.org/science2/ IndexHerbariorum.asp> Acessado em 4/ 7/2006.

IBGE - Instituto Brasileiro de Geografia e Estatística. 1977. Geografia do Brasil. Região Nordeste. Rio de Janeiro, Vol. 2. 
Meerow, A. W. 2004. Alliaceae, Amaryllidaceae. In: Smith, N.; Mori, S. A.; Henderson, A.; Stevenson, D. Wm. \& Heald, S. V. (eds.). Flowering plants of the neotropics. The New York Botanical Garden, New Jersey. Pp. 408-412.

Meerow, A. W. \& Snijman, D. A. 1998. Amaryllidaceae. In: Kubitzki, K. (ed.). The families and genera of vascular plants. Monocotyledons - Lilianae (except Orchidaceae). Hamburg. Pp. 83-110.

Meerow, A. W.; Van Scheepen, J. \& Dutilh, J. 1997. Transfers from Amaryllis to Hippeastrum (Amaryllidaceae). Taxon 46(1): 15-19

Oliveira, R. S. 2006. Flora da Cadeia do Espinhaço: Zephyranthes Herb. e Habranthus Herb. (Amaryllidaceae). Dissertação de Mestrado. Universidade de São Paulo, São Paulo.

Preuss, K. D. 1999. The genus Griffinia Ker Gawler (Amaryllidaceae), revisited. Herbertia 54: 51-66.

Preuss, K. D. \& Meerow, A. W. 2000. Griffinia alba (Amaryllidaceae), a new species from northeastern Brazil. Novon 10: $230-233$.
Preuss, K. D. \& Meerow, A. W. 2001a. A closer look at Griffinia espiritensis Ravenna (Amaryllidaceae). Herbertia 56: 119-126.

Preuss, K. D. \& Meerow, A. W. 2001b. Two new white-flowered Griffinia species. Herbertia 56: 127-131.

Ravenna, P. F. 1970. Contributions to south american Amaryllidaceae III. Plant Life 73-104.

Ravenna, P. F. 1991. New species of Nothoscordum (Alliaceae) - IX. Onira 3(7): 19-21.

Ravenna, P. F. 2000a. Tocantinia and Cearanthes, two new genera, and Tocantineae new tribe, of brazilian Amaryllidaceae. Onira 5(3): 9-12.

Ravenna, P. F. 2000b. Five new species in the genus Griffinia (Amaryllidaceae). Onira 4(5): 19-22.

Ravenna, P. F. 2002. New species of Nothoscordum (Alliaceae) - XX. Onira 7(7): 42-45.

Traub, H. P. 1962. Key to the subgenera, alliances and species of Hymenocallis. Plant Life 18: 55-72.

Traub, H. P. 1963. The genera of Amaryllidaceae. American Plant Life Society, La Jolla. 


\section{Material ADicional CONSUltado}

O número entre parênteses representa o táxon de acordo com a lista numérica de espécies no presente trabalho.

A.Alves-Araújo et al. 17 (8); 18 (8); 21 (8); 25 (8); 29 (8); 30 (5); 31 (5); 32 (8); 33 (2); 34 (5); $36(3) ; 37$ (1); 39 (8); 40 (6); 43 (4); 44 (5); 45 (3); 47 (8); 48 (8); 49 (6); 50 (3); 51 (8); 52 (5); 53 (2); 54 (9); 59 (5); 61 (8); 62 (2); 64 (8); 65 (8); 66 (2); 67 (3); 68 (5); 69 (3); 70 (3); 71 (3); 76 (10); 176 (8); A. Amorim et al. 1350 (1); A. Barreto s.n. (ASE 298) (8); A. Carvalho et al. s.n. (CEPEC 1960) (3); A. Castellanos 23039 (2); A. Conceição 616 (7); 898 (7); A. Dores 117 (20); A. Duarte \& E. Pereira 9315 (8); A. Eupunino 199 (15); A. Fernandes \& A. Castro s.n. (EAC 9371) (5); A. Ferreira \& M. Marques 82 (6); A. FreireFierro et al. s.n. (SPF 2077)(8); A. Gehrt s.n. (4); A. Gentry 50396 \& E. Zardini (16); A. Gomes et al. 300 (5); A. Heller 966 (16); A. Krapovickas et al. s.n. (IPA 26306) (8); A. Laurênio et al. 1174 (10); A. Lima s.n. (RB 113572) (7); A. Rapini et al. 364 (5); A. Sacramento 225 (8); 279 (8); 239 (8); 586 (8); A. Santos 258 \& M. Stapff (3); A. Silva 530 (2); Andrade-Lima 7379 (3); B. Bennett 3577 (16); B. Pickel 2907 (11); B. Pickel s.n. (IPA 3541) (10); B. Stannard et al. 50825 (7); C. Correia et al. 204 (8); C. Costa \& J. Costa 127 (8); C. Eugênio 21 (6); 37 (8); C. Zickel et al. s.n. (PEUFR 17781) (8); D. AndradeLima 4530 (10); 7131 (8); 13487 (2); D. Araújo et al. 1956 (8); D. Carneiro et al. 49 (4); D. Pimentel et al. 38 (8); 73 (8); E. Borba et al. 2188 (8); E. Carneiro 111 (8); 367 (10); E. Gomes 154 (3); 344 (10); E. Heringer \& N. Lima s.n. (JPB 2628) (7); E. Miranda et al. 10 (8); E. Santos 247 (6); E. Smidt 277 \& U. Silva-Pereira (7); E. Tenório 116 (10); F. Alemão \& M. Cisneiros 1529 (5); 1530 (7); F. Cowell 646 (16); F. França 1839 (4); F. França et al. 5293 (5); 5498 (5); F. Hoehne \& A. Gehrt s.n. (4); F. Villarouco et al. 174 (8); G. Barroso s.n. (RB 185203) (2); G. Costa-Lima 3 (2); G. Foetius 3276 (5); G. Hatschbach 53647 (1); 69792 (1); G. Hatschbach 46913 \& O. Guimarães (1); G. Hatschbach et al. 57050 (15); 67438 (13); G. Lewis et al. 939 (6); G. Martinelli et al. 5286 (17); 5451 (6); Grupo Pedra do Cavalo [Scardino et al.] 730 (8); G. Ray 1039 (16); G. Ray 31 \& E. Gibney (20); 84 (16); G. Sousa et al. 516 (2); G. Viana 433 (10); 461 (1); 932 (10); I. Pontual 1735 (6); J. Dutilh s.n. (UEC 23097) (1); J. Hage 105 (8); J. Hage \& H. Brito 1456 (6); J. Jardim et al. 543 (1); J. Stehmann et al. (UEC 72580) (4); K. Andrade et al. 309 (5); 330 (2); K. Yamamoto et al. s.n. (UEC 14257) (8); L. Costa s.n. (UEC 28932) (8); L. Félix \& E. Santana 2839 (8); L. Lima-Verde \& R. Oliveira 135 (3); L. Lima-Verde \& R. Oliveira 25, 138 (3); L. LimaVerde et al. 855 (7); L. Mattos Silva \& T. Santos s.n. (CEPEC 768) (1); L. Mattos-Silva et al. 246 (1); L. Mesquita s.n. (IPA 28238) (8); L. Noblick \& Lemos 2925 (3); L. Queiroz \& N. Lemos s.n. (HUEFS 6714) (8); L. Queiroz 1281 (5); L. Queiroz et al. 1419 (5); 7046 (5); L. Silva et al. 90 (8); 118 (8); L. Xavier s.n. (JPB 1192) (8); Löfgren 786 (8); M. Andrade 577, 579 \& M. Vanilda (3); 578 (5); M. Balick et al. 4305 (20); M. Correia 430 (8); M. Grillo et al. 129 (8); M. Guerra \& L. Félix 1413 (10); M. Junqueira et al. 143 (5); M. Rodal et al. 468 (5); 765 (5); M. Rodrigues 19 \& L. Sena (5); M. Tschá 745 (8); M. Tschá 599 \& D. Pimentel (8); M. Tschá et al. 547 (8); N. Melo s.n. (3); P. Sano \& E. Lughadha s.n. (HUEFS 50931) (20); P. Sano s.n. (HUEFS 50929) (7); R. Bedi 314 (3); R. Forzza et al. 2609 (6); R. Harley \& A. Giulietti 28211 (8); R. Harley 16546 (20); R. Harley et al. 2712 (4); 25711 (5); 25712 (18); 26699 (3); 50421 (7); R. Harley et al. s.n. (HUEFS 50930, SPF 50421) (7); R. Lima et al. s.n. (PEUFR 7139)(8); R. Lyra 210 (5); R. Lyra-Lemos et al. 6702 (5); R. Mello-Silva et al. 1529 (6); R. Pinheiro 1441 (8); 1994 (8); 2175 (23); R. Vieira et al. 1519 (16); S. Cordovil et al. (UEC 106057)(7); S. Lira et al. 96 (8); S. Mori et al. 10522 (15); S. Vinha 86 (13); Sem coletor 1204 (10); T. Cavalcanti et al. 923 (16); T. Nunes et al. 1512 (6); T. S. 1805 (15); T. S. Santos 927 (12); T. Santos 1822 (6); T. Santos 415 (2); V. Fevereiro et al. s.n. (JPB 544) (8); V. Lima \& A. Rita s.n. (IPA 50870) (10); W. Ganev 2931 (20); W. Hoehne s.n. (20); 5458 (9). 